\title{
MARXISMO Y SOCIALISMO MEXICANO \\ EN REDES, DE PAUL STRAND \\ Y CARLOS CHÁVEZ, CON MÚSICA \\ DE SILVESTRE REVUELTAS
}

\author{
Leonora Saavedra \\ University of California-Riverside
}

edes, película mexicana ideada y filmada por el fotógrafo $_{\text {modernista Paul Strand en } 1934 \text {, es conocida entre los }}$
estudiosos de cine como una obra fundamental -fallida en
opinión de algunos - del cine mexicano. ${ }^{1}$ Entre músicos, se le
conoce sobre todo por la espléndida música que para la banda
sonora compuso Silvestre Revueltas, la cual ha ocupado un lugar
importante en la música mexicana de concierto gracias a la suite
que sobre la música original hizo el director de orquesta Erich
Kleiber. ${ }^{2}$ Sólo recientemente hemos escuchado la banda sonora
del film, ${ }^{3}$ así como "una reconstrucción de lo que debió haber

Fecha de recepción: 19 de agosto de 2019

Fecha de aceptación: 8 de octubre de 2019

\footnotetext{
${ }^{1}$ Véase, por ejemplo, García Riera, Historia documental, t. I, pp. 70-71, y REYes, Medio siglo de cine, p. 188.

2 Sobre Revueltas y Redes véase TeIbler-Vondrak, Revueltas Musik für Bühne; Contreras Soto, Silvestre Revueltas en escena, y Kolb-Neuhaus, "Silvestre Revueltas's Redes". La música de Revueltas está publicada por Peer Southern International Co.

${ }^{3}$ El DVD de la película restaurada está incluido en Krippner, Paul Strand in Mexico. Un DVD con la banda sonora "re-creada" por el PostClassical Ensemble bajo la dirección de Ángel Gil-Ordóñez está editado por Naxos.
} 
conformado" la versión de concierto que el mismo Revueltas hiciera, basada en materiales manuscritos. ${ }^{4}$ La película se ocupa de las tribulaciones de un grupo de pescadores pobres y explotados de las orillas del río Papaloapan. Las inclinaciones políticas de izquierda de Revueltas lo han ligado en la mente de muchos con el contenido político del film. ${ }^{5}$ Estudios cuidadosos publicados por Eduardo Contreras Soto y James Krippner sobre la génesis de casi un año de la película han mostrado que la asociación artística del compositor con los creadores de Redes fue tardía, y la música, un elemento creado prácticamente a posteriori. ${ }^{6}$ Krippner, en particular, ha señalado cómo fue otro compositor, Carlos Chávez, quien contrató a Strand para llevar a cabo la filmación, procuró y administró el apoyo económico, y ayudó a la resolución de los problemas logísticos que la película presentó.

Redes fue producida de acuerdo a lineamientos educativos que fueron producto de la Secretaría de Educación Pública (SEP) bajo la dirección de Narciso Bassols (1931-1934), y de Chávez mismo, como director del Departamento de Bellas Artes (DBA) (1933-1934). Redes es no sólo un film sobre sino, sobre todo, para los trabajadores. El objetivo de este ensayo consiste en colocar la creación intelectual y física de Redes en el contexto de las ideas políticas y sociales de Bassols, Chávez y, como resultado de su cercanía a éstos, Strand. Más particularmente, mostraré cómo el argumento de la película y su misma cinematografía siguen fielmente la teoría clásica marxista sobre el capitalismo y la explotación y enajenación del trabajador en él, atendiendo

${ }^{4}$ Grabada en el CD Silvestre Revueltas, Orquesta Sinfónica de la Universidad de Guanajuato. Véase el texto de Kolb, "Los tres caminos", que acompaña la grabación, p. 17. Para una reseña de este disco que cuestiona la presentación de esta partitura como la "versión original de concierto", véase CONTRERAS SOTO, "Tres propuestas revueltianas".

${ }^{5}$ Sobre las actividades políticas de Revueltas en México véase, entre otros, Revueltas, "La Liga de Escritores".

${ }^{6}$ Contreras Soto, Silvestre Revueltas en escena, pp. 73-174; Krippner, "Traces, Images and Fictions"; Krippner, "Carlos Chávez and Paul Strand". 
a la visión colectivista de la SEP de Bassols. Para ello haré un recuento de las actividades del fotógrafo en México, de su paulatina radicalización política y de la génesis de Redes. Discutiré los lineamientos de la SEP dentro de los cuales trabajó, utilizando documentos de archivo. Haré posteriormente una lectura del film analizando el mensaje político del mismo. Finalmente, discutiré la creación o utilización de Revueltas de significadores musicales que facilitan la empatía del espectador, canalizan su respuesta emocional al mensaje político de los creadores del film y anclan su percepción en el contexto específicamente mexicano del mismo.

\section{STRAND EN MÉXICO}

Strand llegó a México a finales de 1932.7 Chávez y él se habían conocido probablemente en Nueva York, en algún momento de los dos años que el compositor pasó en esa ciudad, de 1926 a 1928. ${ }^{8}$ Se reencontraron en Taos, Nuevo México, donde Chávez estuvo en 1931 y el fotógrafo pasó los veranos de 1930, 1931 y 1932. Ambos pertenecían al grupo de intelectuales y artistas que frecuentaban a Mabel Dodge Luhan, mecenas de arte y figura social, cuyo círculo contaba con artistas como D. H. Lawrence, Georgia O'Keeffe y Leopold Stokowski. Siendo director del Conservatorio Nacional de Música en 1932, Chávez ayudó a Strand a cruzar la frontera con sus materiales de trabajo, e intercedió ante Bassols para organizar, del 3 al 15 de febrero de 1933, una exposición de sus fotografías.

\footnotetext{
7 Sobre Strand, incluyendo su periodo en México, véase Busselle y STAck, Paul Strand, Southwest; NAGgar y Ritchin (eds.), México Through Foreign Eyes; Strand y Tomkins, Paul Strand: Sixty Years; Rosenblum, "Strand/ Mexico"; Stange (ed.), Paul Strand; y Tomkins, "Profiles".

${ }^{8}$ Véanse las cartas de Rebecca Strand a Chávez del 3 de enero de 1929 y 18 de marzo de 1930, AGN, CC, serie correspondencia personal, c. 11, vol. III, exp. 99.
} 
Strand calculó que 3000 personas asistieron a la exposición en la Sala de Arte de la SEP en el centro de la ciudad de México, un amplio espacio con puertas que daban directamente a la calle. Muchos años después, Strand recordaría:

Fue una de las exposiciones más interesantes y más satisfactorias que he tenido, a pesar de que sólo duró un par de semanas [...]. Estando a nivel de la calle, la gente entraba por una puerta, recorría la exposición y salía por la otra. Se convirtió en parte de la calle. Todo tipo de gente asistió: policías, soldados, mujeres indígenas con sus bebés, y así. Era una exposición a la que la gente pobre podía entrar sin problema. [...] No sé lo que pensarían de las fotografías. En todo caso nunca he tenido un público así en ninguna otra parte o en ningún otro momento de mi vida. ${ }^{9}$

Poco tiempo después, Chávez fue nombrado jefe del Departamento de Bellas Artes (DBA), sumando este puesto a los de director del Conservatorio, también dentro de la SEP, y director de la Orquesta Sinfónica de México, orquesta independiente que había fundado en 1928. En mayo, Chávez otorgó a Strand un puesto como maestro de fotografía en escuelas primarias. Ese mismo mes Strand escribió un ensayo para el catálogo de una exposición de pinturas de niños y adolescentes de cinco de los centros culturales activos en barrios pobres de la ciudad de México desde los años veinte. ${ }^{10}$ Strand decía observar en los

9 CCP, PSC, AG 17:37 serie miscelánea, “Tape-Recorded Interview with Paul Strand. November 1971. Furnished by the Archives of American Art”. Cinta 1, entrevistador Milton Brown, transcripción en mecanuscrito, p. 25. Documentos internos de la SEP mencionan un total de 9000 visitantes a lo largo de 12 días. Krippner, Paul Strand in Mexico, p. 38. Miembros del círculo de Chávez, Revueltas y el pintor Gabriel Fernández Ledesma, así como el director y autor de teatro Harold Clurman contribuyeron con sendos ensayos al catálogo de la exposición. Todas las traducciones son mías.

10 Paul Strand, "El significado de la pintura infantil", en CCP, PSC, Archive Group 17: 31 serie scrapbooks, Scrapbook 2 1929-1936, Catálogo de la 
niños una madurez precoz y una seriedad en las pinturas que atribuyó a su cercanía con las precarias condiciones de trabajo de sus padres.

En junio de 1933, Chávez comisionó a Strand para inspeccionar las actividades artísticas en las escuelas rurales de Michoacán, comisión que el fotógrafo aprovechó para tomar las fotografías del centro y occidente de México que en 1940 se publicarían como Photographs of Mexico. ${ }^{11}$ Su guía en el desempeño de la comisión fue Agustín Velázquez Chávez, sobrino de Carlos Chávez. Un memorándum del DвA muestra que Strand debía "hacer estudios especiales y juntar la información necesaria para elaborar un plan para llevar a cabo películas educacionales", lo que indicaría que en este momento Chávez estaba interesado ya en realizar una película sobre la producción y circulación de las artes y oficios por los cuales Michoacán es conocido, como lacas, textiles, alfarería y la construcción de instrumentos musicales. ${ }^{12}$

En su reporte al DBA Strand manifestó estar sorprendido por la combinación de una extraordinaria habilidad artesanal con diseños estereotipados de flores, frutas y bordes con patrones "pseudo-aztecas" que encontró en Michoacán. Se mostró igualmente desilusionado por la fabricación de objetos de escasa o ninguna utilidad para los artesanos, como polveras y juegos de ajedrez. Alarmado por el peligro que la apertura de mercados locales e internacionales para dichos productos representaba para el carácter y la originalidad de las artes populares, Strand colocó la situación en su reporte en el marco de "el presente sistema

primera exposición de pintura de los Centros Culturales, México, Dirección General de Acción Cívica, 1933, pp. s.n. Agustín Velázquez Chávez enseñaba arte en uno de ellos.

${ }^{11}$ Strand, Photographs of Mexico.

12 CCP, PSC, Archive Group 17: 31 serie scrapbooks, Scrapbook 2 1929-1936, memorándum de Carlos Chávez a Paul Strand, 2 de junio de 1933. 
económico de explotación comercial y el esclavizamiento de la gente a éste". ${ }^{13}$

Finalmente, a su regreso de Michoacán, según narra él mismo:

Chávez me llamó a su oficina y me dijo "Estamos interesados en hacer películas en México. Es una idea mía que he acariciado ya por algunos años. Creo que podemos comenzar ya. Lo que queremos es hacer una serie de películas -llamémoslo un plan quinquenal-; nos gustaría que tú te hicieras cargo, y juntos decidiremos qué clase de películas deberán ser.”... Yo no tenía ni idea de cómo hacer películas. Y no tenía idea alguna sobre qué tipo de películas debían $\operatorname{ser}[\ldots] \cdot{ }^{14}$

Chávez creó la Oficina de Fotografía y Cinematografía del DBA para realizar su plan quinquenal y contrató a Strand como su director en diciembre de 1933. Habiendo recibido el encargo de transformar este plan en películas concretas, Strand y Velázquez idearon la narrativa general de Pescados, título original de Redes, durante una visita a Alvarado, en los bordes del río Papaloapan. ${ }^{15}$ Ésta sería la primera película del plan.

Strand tenía una película documental y 16 años de experiencia como camarógrafo free lance de noticieros, pero poca como

13 CCP, PSC, Archive Group 17: 31 serie scrapbooks, Scrapbook 2, 19291936, "Report of Paul Strand on Trip to Michoacán, June, 1933", mecanuscrito, p. 3.

14 “Tape-Recorded Interview”, pp. 25-26. En esta entrevista tardía Strand ubicó el acontecimiento en el verano de 1933, pero en una carta a Ignacio García Téllez del 28 de febrero de 1935 refirió la conversación a mayo de 1933 véase AGN, CC, serie correspondencia personal, c. 11, vol. III, exp. 98. El original en inglés de la carta, del 7 de febrero se encuentra en una colección privada y está reproducida en KrIPPNER, Paul Strand in Mexico, pp. 339-359.

15 La primera narrativa, con poco contenido político-social, se tituló Robalo; véase AGN, CC, serie OSM INBA, c. 2, vol. II, exp. 26, “Argumento de El Robalo”, mecanuscrito. Strand y Chávez se refirieron al film como Pescados durante toda la filmación. La película se retituló Redes en posproducción. 
director de cine. A invitación de Strand, Henwar Rodakiewicz viajó desde Los Ángeles para asistir a Strand en la confección de los diálogos y el guión, proceso que duró de octubre a enero de 1934 y durante el cual Strand y Rodakiewicz añadieron secuencias y expandieron ideas de la historia original. Cuando Rodakiewicz se vio obligado a regresar a Los Ángeles, Fred Zinnemann se unió al equipo de Strand como director, con Emilio Gómez Muriel como codirector y asistente administrativo. Strand fue el cinematógrafo y autor intelectual del film. ${ }^{16}$ El equipo comenzó la filmación en enero de 1934 y se mantuvo en locación hasta noviembre de ese año. En junio Rodakiewicz regresó a Alvarado como editor del film junto con Ned Scott, fotógrafo de foto fija. ${ }^{17}$ Los actores fueron, en su mayor parte, los pescadores mismos, con excepción de Silvio Hernández (Miro), quien era un estudiante, y el actor profesional David Valles González, quien representaba a Anselmo. Documentos de archivo depositados en Arizona indican que narrativa, guión y diálogos se modificaron frecuentemente hasta, por lo menos, mediados de $1934 .^{18}$

Strand se había iniciado en la fotografía alrededor de 1908 con Lewis Hine, quien entonces documentaba la explotación de los niños trabajadores en Estados Unidos. Sin embargo, sus

16 Velázquez y Julio Bracho fueron contratados como asistentes a la vez que aprendices del oficio, pero dejaron el proyecto en diciembre de 1933 y marzo de 1934 respectivamente. KrIPPNER, “Traces, Images and Fictions”, p. 377.

17 Las fotografías fijas de Ned Scott de las configuraciones visuales ideadas por Strand como cinematógrafo se conocen más ampliamente que las imágenes extraídas del film.

18 Strand solicitó un presupuesto y empezó la filmación con base en la séptima revisión del guion, hecha por Strand y Rodakiewicz. Véanse las diferentes versiones del guion en CCP, PSC, Archive Group 17:28 serie films, exp. 1, The Wave: Correspondence, 1951-1974; exp. 2, The Wave: Cutting logs (Opening - Seq. E); exp. 3 The Wave: Cutting logs (Seq. F - Seq. L); exp. 4, The Wave: Dialogue; exp. 7, The Wave: Script (early?) handwritten; exp. 8, The Wave: Shooting script, handwritten; 9, The Wave: Shooting script; exp. 10, The Wave: Spanish script and subtitles. 
primeras fotografías no revelan un contenido social. Van de la fotografía difusa a imitación de la pintura impresionista, a una fotografía cubista, abstracta, constructivista, creada a partir del arreglo formal de los objetos fotografiados y del claroscuro obtenido en el proceso de revelado e impresión. Del cubismo, Strand aprendió "cómo se construye una imagen, en qué consiste una imagen, cómo se llenan los espacios, y como todo debe tener una cierta unidad". ${ }^{19}$ Ésta fue una preocupación artística del fotógrafo durante la década de 1910, incluso en las fotos en las que podría verse cierto contenido social, como Wall Street, en la que Strand captura un instante del movimiento de pequeñas figuras humanas en relación con la estructura formal de un edificio y sus enormes ventanas rectangulares. Sobre esta etapa de su carrera, diría Strand más tarde: "Uno de los elementos con los que quería trabajar por aquel entonces era gente moviéndose en la calle [...] Quería ver si podría organizar una imagen de ese tipo de movimiento de una manera abstracta y controlada". ${ }^{20}$

Strand aplicó esta misma idea a su primera película documental, Manhatta, de 1921, donde el movimiento de gente, barcos o columnas de vapor se percibe en yuxtaposición a un cuadro o fondo abstracto. Más tarde, Strand aplicó ese constructivismo abstracto a sus fotografías de paisajes de Nuevo México, en los que nubes, tierra y cielo se convierten en elementos formales integrados en un todo artístico. Como veremos más adelante, este principio guió también la cinematografía de Redes.

Con el inicio de la Depresión en Estados Unidos en 1929, Strand, como tantos otros artistas, perdió paulatinamente la fe en la promesa de la modernidad, la vida urbana y el capitalismo. En Nueva York se había interesado, más como espectador que como participante, por los experimentos teatrales del Groupe Theatre de Harold Clurman, que estaba buscando un tipo

19 Citado en Tomkins, "Profiles”, p. 48.

20 Citado en Tomkins, "Profiles", p. 48. 
de teatro que reflejara consecuente y directamente los problemas sociales a los que se enfrentaban: "El Groupe Theatre era algo en lo que me había interesado mucho antes de ir a México. De hecho había participado como espectador en el desarrollo de ese Teatro y había escuchado a Harold Clurman y a otros hablar acerca de él a los actores que asistían a éste". ${ }^{21}$

Pero fueron su contacto y su participación en los experimentos sociales que se llevaban a cabo en México los que guiaron y aceleraron su radicalización política. ${ }^{22}$ Así, en una carta de noviembre de 1933 al matrimonio Baasch, Strand explicó:

[...] la historia [de Pescados] es [...] una verdadera historia de lucha $[\ldots]$ que termina en una nota de acción colectiva solidaridad -algo en lo cual yo creo- y en una crítica al capitalismo, un sistema que detesto. Por todo lo cual ustedes percibirán que mi interés en las fuerzas sociales de hoy ha crecido considerablemente durante este año. Esto es porque no veo cómo nadie, el artista en particular, puede $[\ldots]$ estar [...] por encima de esta lucha [...] en algún momento debemos [...] saber cuál es nuestra posición -yo no sé si pueda

21 “Tape-Recorded Interview”, p. 31. Strand buscó el consejo de Clurman como autor dramático, es decir, sobre cómo obtener el mayor efecto a partir de los personajes y la historia, pero nunca compartió con él sus opiniones políticas del mismo modo en que las compartiría, por ejemplo, con Ted Stevenson [véase CCP, PSC, Archive Group 17: 22 serie correspondencia personal, exp. 1, carta de Philip (Ted) Stevenson a Paul Strand, abril 24 de 1933] o con Kurt e Isabel Baasch, como se discutirá enseguida. Clurman sugirió cómo introducir al personaje de Miro para crear una persona simpática empujada por las circunstancias y no "un alborotador en el sentido peyorativo, capitalista, de la palabra”, CCP, PSC, Archive Group 17: 14, serie correspondencia personal, exp. 14, carta de Paul Strand a Harold Clurman, 2 de enero de 1934.

22 Los comentaristas de la obra de Strand tienden a minimizar o a explicar en términos estéticos el radicalismo político que Strand adquiriría en México. Ejemplo de ello son Trachtenberg, "Introduction", o Szegedy-Maszak, Toward a Deeper Understanding. La excepción a ello son los trabajos de KripPner y Rohrbach, “Art for Society's Sake”. 
ser llamado comunista, pero encuentro las ideas de Marx, que he estado leyendo últimamente, muy verdaderas $[\ldots]^{23}$

Unas semanas más tarde, plenamente sumergido en la concepción de Redes, Strand escribió de nuevo, expandiéndose sobre el pensamiento social recientemente adquirido:

Sólo les puedo decir lo que yo creo -lo que durante un año aquí solo lejos de Nueva York se ha convertido en parte de mi fe. Comenzaré negativamente-, no creo más en el individualismo [...] no creo en la democracia en conjunción con el capitalismo [...] Creo que la gente serán seres humanos completos cuando trabajen juntos [...] en el convencimiento de que la vida humana debe ser colectiva [para ser] la base del crecimiento individual. Y eso significa un cambio completo del sistema económico [...] y hay sólo una clase que lo puede transformar: los trabajadores [...] ya sea la labor de los músculos o del cerebro [...] He obtenido mucha claridad de mi lectura sobre Marx y su programa. Él era un [...] materialista, es decir que su evaluación del comportamiento humano se puede remitir a las luchas históricas relacionadas con la producción de la riqueza. ${ }^{24}$

Strand expresó así su nueva interpretación de la sociedad como estructura colectiva, la primacía del sistema económico reinante, la misión transformativa del trabajador, y su concepción del trabajador intelectual -el artista- como miembro de la clase trabajadora. Desilusionado de las promesas que el capitalismo hace al individuo y consciente de la distribución desigual de los recursos, a finales de 1933 Strand compartía con Chávez y Bassols una concepción materialista de la sociedad, es decir,

23 CCP, PSC, Archive Group 137:2 serie correspondencia, exp. 2, carta de Paul Strand a Kurt e Isabel Baasch, 26 de noviembre de 1933. Strand leía a STRACHeY, The Coming Struggle, y a Hook, Towards the Understanding. 24 CCP, PSC, Archive Group 137: 2 serie correspondencia, exp. 2, carta de Paul Strand a Kurt e Isabel Baasch (17 dic. 1933). 
una comprensión de la primacía del modo de producción de la riqueza respecto a las ideas dentro de una sociedad, con el trabajo como elemento central. Strand depositó su fe, en cambio, en una forma socializada y colectivista tanto de la economía como de la existencia misma.

\section{MATERIALISMO FILOSÓFICO Y ESTADO ACTIVISTA}

El socialismo con el cual experimentaban teórica y legalmente los dirigentes políticos e intelectuales del aparato estatal mexicano en la década y media que siguió a la revolución de 1910 se acerca más, en retrospectiva, a una socialdemocracia que a la etapa de transición entre capitalismo y comunismo del marxismo-leninismo clásico, es decir, consiste en la socialización de industrias básicas a través de su estatización y la creación de una red social y legal de protección a las clases trabajadoras. A nivel superestructural y sobre todo educativo, el socialismo se entendía como la aplicación sistemática de la racionalidad a los procesos sociales y a la educación. La educación socialista que se debatió en México en la transición de los años veinte a los treinta, y que se hizo constitucional durante un tiempo en diciembre de 1934, era decidida e incluso agresivamente científica y laica; una educación basada en la razón y en la ciencia aplicadas a la tecnología y al entendimiento de los procesos humanos. ${ }^{25}$ Era una educación que abriría las mentes a la modernidad, erradicaría la superstición y permitiría a las clases trabajadoras competir eventualmente en el mercado internacional. ${ }^{26} \mathrm{La}$ educación socialista estaba dirigida, en particular, a desmontar el control que la Iglesia católica tenía sobre la educación nacional y a convertir a ésta en una educación federal y por lo tanto homogénea, paso indispensable en la generación de una nación. Es esta

25 VÁzQuez de KNAUth, Nacionalismo y educación, pp. 152-154.

26 BRITTON, Educación y radicalismo, p. 12. 
concepción de la educación la que llevó al estado a enfrentarse numerosas veces con líderes religiosos, maestros de escuelas privadas e incluso federales y asociaciones de padres de familia, y la que eventualmente causó la caída de Narciso Bassols como secretario de Educación Pública en 1934.27

Bassols era, filosóficamente hablando, materialista, lo que explica su apego a la razón científica. En cuanto a procesos económicos, sociales y artísticos, Bassols los entendía, como materialista, como procedentes de la base a la superestructura, de la economía a las relaciones sociales y de allí a las ideas, incluyendo a la religión y a la cultura expresiva, como el arte. Por ejemplo, en un interesante discurso dirigido a los maestros y misioneros rurales que se ocupaban, desde la administración de Vasconcelos en la SEP, de la recolección con miras a la preservación de las artes populares, Bassols declaró sin reserva alguna la futilidad de tal empresa:

[...] es indispensable percibir con igual claridad que las manifestaciones folklóricas del pueblo mexicano sólo deben fomentarse en tanto que no constituyan un lastre opuesto al desenvolvimiento económico de los campesinos [...] las artes populares no son sino medios de expresión de la vida social”. ${ }^{28}$

Bassols abrigaba dudas sobre el materialismo histórico y la predicción de un régimen de producción sin propiedad privada, por lo que no abogó por éste. Para él el problema no era la propiedad privada en sí, sino el individualismo agresivo del liberalismo económico, la irracionalidad del mercado capitalista

27 Sobre Bassols y el pensamiento social y educativo de su época véanse las obras de Bassols editadas por Aguilar Monteverde, Luna Arroyo, Paz Sánchez y Silva Herzog; y los estudios de BRITTON, Educación y radicalismo; RABY, Educación y revolución social; VAUGHN, La política cultural y VÁZQUEZ DE KnaUTH, Nacionalismo y educación.

${ }^{28}$ Bassols, “Conferencia sobre las Misiones Culturales”, pp. 175-176. 
y la división de la sociedad en clases, con sus correspondientes desigualdades económicas y sociales. A diferencia de los líderes políticos del siglo xIx, quienes habían creído que el liberalismo económico y una política de laissez-faire por parte del Estado eran los medios de combatir la pobreza en México, para Bassols el país necesitaba un gobierno activista, que se transformara de un organismo político en uno que interviniera en asuntos económicos y sociales. ${ }^{29}$

Después de la Revolución, la sep fue la instancia encargada de elaborar una política cultural que educara a las clases trabajadoras en sus nuevos derechos. Su arma principal fueron las escuelas rurales. En 1932 la sEP de Bassols tenía una política aún más ambiciosa, el énfasis cambió de los problemas sociales a los económicos; se habló menos de la incorporación del indígena y más del mejoramiento de los métodos productivos. ${ }^{30}$ Más aún, en palabras de Bassols: "Quiero referirme al aspecto esencialmente económico que nuestra educación rural tiene y que consiste en tratar de modificar los sistemas de producción, de distribución y de consumo de la riqueza [...]". ${ }^{31}$

Así, durante la administración de Bassols, de octubre de 1931 a mayo de 1934, a la par de expandir la educación federal rural, la SEP se impuso como objetivo educar a la población (a los niños en las escuelas y a los padres alrededor de éstas) en prácticas dedicadas a transformar los sistemas rurales de producción aumentando su productividad por medio de tecnología pero distribuyendo la riqueza común en forma socializada -a manera de las comunidades indígenas- $-{ }^{32} \mathrm{~A}$ decir del historiador John Britton, el objetivo final de Bassols habría sido la unidad nacional sobre la base de una mezcla de marxismo y colectividad

29 BRITTON, Educación y radicalismo, p. 25.

${ }^{30}$ RABY, Educación y revolución social, p. 36.

31 Bassols, "El problema educativo", p. 176 (discurso pronunciado 19 jul. 1932).

32 Bassols, "El problema educativo", p. 179. 
indígena, en combinación con tecnología occidental aplicada a la producción de la riqueza, y la ciencia y la razón aplicadas a la transformación de las mentalidades y las costumbres..$^{33}$

Chávez, quien era no sólo miembro del equipo de Bassols sino también su protegé, creía que el activismo social por medio del arte era también un deber del artista y se aplicó intelectualmente a conciliar el materialismo filosófico y político con el arte y el artista, en particular el artista productor de alta cultura. ${ }^{34} \mathrm{~A}$ finales de septiembre de 1934, cuando su Sinfonía Proletaria y su Corrido El Sol para coro de obreros y orquesta estaba por estrenarse en la inauguración del Palacio de Bellas Artes, Chávez publicó tres artículos en el periódico El Universal como plataforma desde la cual exponer sus ideas sobre el arte, la sociedad y las clases trabajadoras. ${ }^{35}$

Citando el Anti-Dühring de Friedrich Engels y la Contribución a la crítica de la economía política de Karl Marx, Chávez hizo énfasis en la idea de que el hombre es producto de la naturaleza y siguió este argumento hasta sus últimas conclusiones en el materialismo: los individuos no crean su propia conciencia, la conciencia es producto de la sociedad en que vive el individuo. $\mathrm{Si}$ el arte es el producto de una "masa social viva", planteaba, la sociedad debería ser capaz de reconocerse en el arte producido por sus artistas. ${ }^{36} \mathrm{Si}$ no lo puede hacer es porque la burguesía,

33 BRITTON, Educación y radicalismo, p. 53. Véase también BAssols, "El problema educativo", pp. 178-179.

${ }^{34}$ Sobre el pensamiento social de Chávez, véase SaAvedra, "The American Composer".

35 Carlos Chávez, "El arte en la sociedad," El Universal (27 sep. 1934). Reproducido en Carmona (ed.), Carlos Chávez. Escritos, pp. 247-251; Carlos Chávez, "El arte occidental", El Universal (28 sep. 1934). Reproducido en Carmona (ed.), Carlos Chávez. Escritos, pp. 253-258. Carlos Chávez, "El arte proletario”, El Universal (29 sep. 1934). Reproducido en CARMONA (ed.), Carlos Chávez. Escritos, pp. 259-263.

${ }^{36}$ Carlos Chávez, "El arte en la sociedad”, El Universal (27 sep. 1934). Reproducido en Carmona (ed.), Carlos Chávez. Escritos, p. 251. 
sostenía él, impide que la educación y la producción de los trabajadores intelectuales llegue a las clases trabajadoras, manteniéndolas es un estado de ignorancia que les impide tomar conciencia de la injusticia del régimen social.

A la inversa, como trabajadores sin propiedad privada, los artistas no tienen control sobre los medios de distribución libros, cine, radio, salas de concierto- por medio de los cuales su arte llega a la clase trabajadora. Chávez, como Strand, y como muchos otros artistas mexicanos de los años treinta, definía al proletariado como aquellos que trabajan manualmente o (a diferencia del marxismo clásico) intelectualmente a cambio de un salario. Haciendo eco de las ideas de Engels sobre las consecuencias de la moderna división del trabajo en tareas parciales y especializadas, Chávez sostenía que la propia especialización del artista le impedía entender el régimen social en el que vive. Hizo entonces un llamado desde estas publicaciones a los artistas a adquirir una conciencia de clase en solidaridad con la clase trabajadora, y los exhortó asimismo a reconocer y tomar bajo su control la marca que deja en el arte su propia naturaleza social y a producir un arte proletario para el proletariado.

\section{LA EDUCACIÓN SOCIALISTA}

DE LOS OBREROS MEXICANOS

Chávez no era solamente un artista en busca de un credo social sino también, como director del DBA, miembro de la burocracia educativa estatal. Y compartía con Bassols la idea de un Estado activista. Podemos observar en documentos administrativos semiprivados cómo la teoría social del marxismo guió las ideas y la praxis de Chávez como educador. En una serie de documentos relacionados con la fundación y organización de las escuelas nocturnas para trabajadores, por ejemplo, Chávez citó directamente el Anti-Dühring sobre los efectos de la división 
del trabajo durante el capitalismo. ${ }^{37}$ Explicó entonces cómo previamente los artesanos en los gremios habían conservado los aspectos creativos e inventivos de su trabajo, mientras que en el capitalismo la capacidad de invención está en manos de científicos e ingenieros y el trabajador moderno está emocional e intelectualmente enajenado del producto de su labor, ahora estrictamente física, mecanizada y repetitiva.

Dicha amputación de la parte creativa de los trabajadores debía ser aliviada devolviéndoles su capacidad creativa, afectiva e intelectual por medio del aprendizaje y la práctica del arte. Chávez estaba consciente de la dificultad de llegar a este objetivo en ausencia de un cambio real en el modo de producción y en las relaciones sociales: "[...] una regeneración eficaz definitiva de las clases trabajadoras [...] solamente puede lograrse mediante el establecimiento de un régimen de división del trabajo que vaya de acuerdo con la realidad biológica del hombre [...] Por el momento lo único posible parece ser tratar de corregir [...] los males graves que encontramos en las clases trabajadoras". ${ }^{38}$ Chávez consideraba el trabajo puramente mecánico, la falta de conciencia y una propensión a los vicios urbanos, como la bebida, entre los problemas a resolver. Él y el Consejo de Bellas Artes elaboraron un ambicioso plan de trabajo para las escuelas nocturnas, en las que los obreros recibirían educación en historia y cultura-occidental, debemos decir-dedicada a hacerlos más conscientes de su propia sociedad, junto con entrenamiento específico en música, danza, drama o artes visuales.

Es en este contexto que Chávez -probablemente- elaboró el plan quinquenal para la producción de películas educativas para los trabajadores..$^{39} \mathrm{El}$ documento que contiene los lineamientos

37 AGN, CC, serie OSM INBA, c. 2, vol. II, exp. 29, Carlos Chávez, "Las escuelas de arte para trabajadores", mecanuscrito, p. 2.

${ }^{38}$ Chávez, "Las escuelas de arte", p. 2.

39 AGN, CC, serie OSM INBA, c. 2, vol. II, exp. 26, "Plan para la filmación de películas educativas", mecanuscrito. 
del plan es intelectualmente sofisticado aunque sumamente ambicioso en su extensión, y aunque no lleva firma, el estilo de la escritura y la estructura del documento son características de Chávez. Aquí, sin embargo, la influencia de Bassols, con quien Chávez estaba en estrecho contacto en lo que concierne al plan, es quizá más evidente. Sin citar directamente a Marx o a Engels, el documento revela una lectura amplia de los escritos de éstos en economía política. Así, mientras que en sus escritos periodísticos Chávez se mantiene ligeramente por encima de la idea, sin referirse a ella directamente, de que la base económica de la sociedad determina la producción de la conciencia social, en este documento las películas -y la educación de los obreros-deben referirse sin ambigüedad al modo capitalista de producción, tanto en sí mismo como en su papel de agente estructurador de una sociedad dividida en clases sociales antagonistas.

Los lineamientos establecidos para la primera serie de películas no dejan duda alguna sobre la posición filosóficamente materialista que debían presentar a los obreros. Las películas deberían demostrar la habilidad del hombre para emplear recursos naturales en la producción de la riqueza por medio de sus habilidades musculares e intelectuales. Documentarían la producción y la distribución de la riqueza creada por la explotación del mar y la tierra: agricultura, pesca, minería, mostrando al mismo tiempo las diversas regiones de México y la necesidad de almacenamiento, transporte y comercio. El primer objetivo, por lo tanto, era producir una representación objetiva del capitalismo, educando a los obreros por medio de representaciones visuales sobre los medios y las tecnologías de producción, distribución y cambio de la riqueza creada de diferentes maneras: pesca, agricultura, manufactura, etcétera.

Un segundo objetivo era documentar las relaciones sociales de producción dentro del régimen capitalista mediante las cuales la riqueza producida por los obreros contribuye a la prosperidad económica de una clase que no es la suya, dejando 
al productor directo de la riqueza en un estado de pobreza. Las películas dejarían en claro el surgimiento de una clase social que domina la industria y el comercio, y de una clase trabajadora con sus medios de resistencia, los sindicatos. Un tercer y eventual objetivo de esta primera serie sería mostrar a los trabajadores cómo todo alrededor de ellos, incluyendo la comida, el alojamiento, la ciencia y el arte, se relaciona con la producción de la riqueza: en términos marxistas, cómo la superestructura es determinada en última instancia por la base económica.

En conjunto, las películas demostrarían que la educación durante el capitalismo está diseñada para impedir que los trabajadores tomen conciencia de la futilidad de buscar fuentes de bienestar social e individual en la superestructura ideológica en vez de intentar cambiar el ámbito socioeconómico. En este punto de la historia mexicana, cuando la Iglesia católica y el Estado habían apenas salido de la violenta Guerra Cristera, la idea implicaba que los obreros debían dejar de buscar en la religión una fuente de bienestar.

Una segunda serie de películas demostraría la injusticia del actual modo capitalista de producción, "dando énfasis a las situaciones dramáticas y condenables del régimen en vigor". ${ }^{40}$ Finalmente, mientras la primera serie enseñaba una concepción materialista de la sociedad, y la segunda pretendía generar una conciencia de clase, la tercera debía enseñar materialismo histórico: el desarrollo a través de la historia de modos de producción sucesivos, como el feudalismo y el capitalismo, para "mostrar en forma objetiva la posibilidad de un régimen social cuya justicia radique en que todos los hombres trabajan y todos ellos obtienen por igual la satisfacción de sus necesidades", en otras palabras, del socialismo. ${ }^{41}$

\footnotetext{
40 “Plan para la filmación”, p. 5.

41 “Plan para la filmación”, p. 5.
} 
Los lineamientos para el "Plan para la filmación de películas educativas" planteaban que mientras la primera serie estaría destinada a los niños, la segunda y la tercera se pensarían para adultos. Los lineamientos eran ambiciosos, exhaustivos, excesivamente didácticos y muy secos. En un memorándum del 30 de agosto de 1933 Strand y Velázquez plantearon a Chávez no esperar hasta la segunda serie para despertar una conciencia de clase entre los trabajadores, sino mostrarles dentro de la película el estado de explotación en que se encontraban y su sufrimiento y, a consecuencia, propiciar un sentimiento de solidaridad "por razón de la impresión que la película haga [...] en su espíritu [...]”. Asimismo, manifestaban: "[...] creemos que estas películas deben ser hechas para grandes mayorías de personas sencillas a quienes debe mostrárseles los factores económico-sociales, en forma elemental, en una forma directa, inequívoca y sencilla; en una forma quizá molesta para sensibilidades más complicadas." ${ }^{42}$

En una conversación posterior, Strand acordó con Chávez y Bassols que si la audiencia principal de las películas iba a ser la gran masa de personas sin educación superior, los "dieciséis millones de indígenas [y] campesinos”, las películas debían tener personajes y una narrativa que reflejara la vida de los trabajadores, de manera que se reconocieran a sí mismos y a sus problemas. ${ }^{43}$ Finalmente, acordaron también que:

[...] usaríamos las técnicas de filmación más ricas e imaginativas desde el punto de vista estético para hablar a la gente, siguiendo la teoría de que el mejor arte sería el que llegaría a toda la gente, especialmente a este público, con mayor fuerza; y que ése sería el problema a resolver al trabajar. Carlos Chávez es, por supuesto, un artista de primer orden $[. .$.$] y entendió de lo que estaba hablando$

${ }^{42}$ AGN, CC, serie OSM INBA, c. 2, vol. II, exp. 26, memorándum de Paul Strand y Agustín Velázquez a Carlos Chávez, 30 de agosto de 1933, mecanuscrito.

43 “Tape-Recorded Interview”, p. 27. 
[...] el reconocimiento del problema estético como el mejor y único medio de comunicación con el público. ${ }^{44}$

\section{LA ENSEÑANZA SOCIALISTA EN REDES}

Redes es un ejemplo de lo que ahora se llamaría docuficción, es decir, utiliza una historia personal para documentar una situación real. El argumento final es básicamente el siguiente. En medio de gran pobreza un grupo de pescadores en Alvarado, Veracruz, espera con ansia la llegada de los peces para iniciar la pesca. Algunos poseen botes mediocres y redes eternamente remendadas y otros sólo la fuerza de sus cuerpos. Entre ellos se encuentra Miro, cuyo hijo está enfermo. Miro camina por lo que percibimos es una aldea de pescadores pobres hasta llegar al pueblo y pedir un préstamo o adelanto al hombre más rico, el acaparador Anselmo. Éste es el dueño de los botes más grandes y las redes más nuevas y, gracias a su fábrica de hielo, es el intermediario entre los pescadores locales y el mercado nacional. Pero Anselmo, a quien hemos visto checar el estado próspero de su negocio, no presta a Miro el dinero que tan desesperadamente necesita para el doctor. El niño muere; su pequeño ataúd blanco es enterrado mientras que su madre, inmóvil a pesar de su dolor, permanece sentada en una tumba cercana (fotografía 1). Miro lamenta la injusticia de todo ello.

Unos días más tarde, un pescador avisa que la pesca por fin ha llegado. En una larga secuencia, observamos cómo los hombres jalan los botes, se embarcan en el río, extienden sus redes y atrapan a los peces en ellas con gran alegría; sus cuerpos musculosos se tensan por el esfuerzo y la cámara los muestra contra un fondo inmenso de mar y cielo. La aldea entera se regocija: hay pescado suficiente para todos y para vender. Los pescadores se

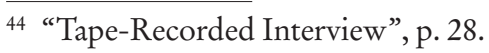


Fotografía 1

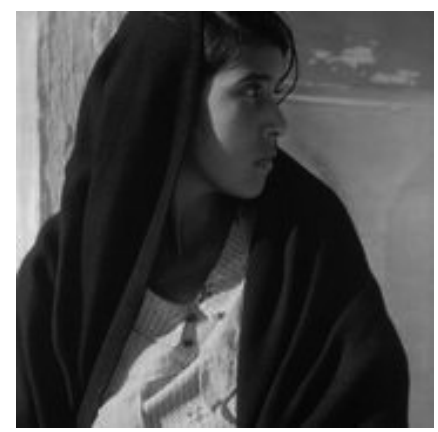

Paul Strand, Woman of Alvarado, Veracruz, 1933. @ Aperture Foundation, Inc., Paul Strand Archive. Susana Ortiz Cobos representó el personaje de la madre del niño, aquí durante el entierro.

apresuran a llevar su abundante pesca al negocio de Anselmo para que sea pesada, sólo para quedar decepcionados por el puñado de centavos que reciben del capataz Mingo por el producto de su labor. Al ser el único comprador de pescado en el pueblo, Anselmo fija el precio que quiere y los hombres no tienen más opción que aceptar.

Los pescadores se resignan a su suerte hasta que Miro, empujado por la injusta muerte de su hijo, sube a unas dunas cercanas y desde allí lanza un discurso poderoso a los pescadores explicando en detalle lo que resultan ser los principios del capitalismo, por supuesto, sin nombrarlo como tal. Miro exhorta a los pescadores a rehusarse colectivamente a vender el pescado al precio que fija Anselmo: unidos pueden exigir una mejor paga. Observamos cómo el político corrupto del pueblo, quien había solicitado a Anselmo una contribución para su campaña, le asegura poder mantener a los pescadores bajo control, pero su propio discurso, claramente demagógico y pronunciado después del de Miro, se enfrenta a la total indiferencia de los pescadores, quienes se dispersan. 
Sin embargo, no todos los pescadores están de acuerdo con el llamado de Miro; muchos se sienten impotentes, otros temen perder lo poco que tienen. En vano Miro los confronta y cuando, desesperado, tira el pescado al suelo, una larga pelea tiene lugar entre ellos. Los hombres se dispersan con la llegada del ejército, pero cuando la pelea está en su punto álgido el político, escondido en una casa cercana, dispara a Miro. Los amigos de éste se lo llevan rápidamente. Anselmo paga pobremente a los pescadores que se quedan, pero trata de comprar su lealtad dándoles la paga de los partidarios de Miro. Este atropello y la muerte de Miro se convierten en el catalizador que une finalmente a los pescadores. En la última secuencia de la película observamos cómo éstos transportan el cuerpo de Miro de regreso al pueblo; una multitud de barcos se unen a esta procesión fúnebre sobre el agua.

Como bien lo señala Eduardo Contreras, Redes no documenta la vida real de los pescadores de Alvarado, ni fue esa su intención. ${ }^{45}$ Por otro lado, tampoco propone la sublevación armada de los pescadores ni la destrucción de la propiedad privada. Muestra, con pretensión de objetividad, lo que en términos marxistas serían las fuerzas productivas de la industria pesquera y las condiciones materiales y relaciones sociales de producción de los pescadores, dentro de una economía capitalista opresora y enajenante, que afecta la salud física y mental de los trabajadores. La película expone cómo el sistema económico trabaja a favor de aquellos que poseen los medios de producción y el monopolio de los procesos de distribución y venta, mientras que documenta la explotación de la labor física -única propiedad- de los pescadores y su falta de conciencia de clase. La película muestra a los pescadores el camino a la unidad de clase. Finalmente, les enseña la esperanza que otorgan la dignidad y la resistencia.

${ }_{45}$ Contreras Soto, Silvestre Revueltas en escena, pp. 136-138. 
Analicemos a guisa de ejemplos algunos de los momentos en que Redes ilustra fielmente las ideas del plan quinquenal para películas educativas. El estilo modernista y constructivista que Strand exhibiera en su fotografía, logrado en Redes por la disposición espacial del sujeto cinematográfico, se despliega en toda su plenitud en ella y es en parte lo que hace a la película tan sorprendentemente bella.

La secuencia de la pesca comienza a los 12 minutos con 25 segundos con una toma de los primeros pescadores que encuentran la pesca remando hacia la orilla del río, sus botes llenos de pescado. Un tumulto de gente de la aldea se precipita hacia los botes. Otros de los hombres cargan las redes en sus botes y reman río adentro; la cámara los sigue mientras extienden sus redes, regresan a la orilla y tiran de las redes atrapando abundantes peces. La película documenta así la industria pesquera, pero la composición de las tomas, al mostrar la figura humana contra un fondo imponente hecho de mar, cielo y arena, provoca en el espectador una reflexión sobre la difícil relación del hombre con la naturaleza. Al mostrar esta lucha Strand revela la influencia de Robert Flaherty, pero va más allá que éste al adentrarse en lo social e incluso en lo político. ${ }^{46}$ Más precisamente, el espectador se convierte en testigo presencial de la transformación de la naturaleza en riqueza por medio del trabajo físico del hombre -creador de plusvalía-. Muchos pescadores, como Miro, no cuentan más que con eso, lo que es una idea central de la economía política. Tomas cortas de peces atrapados en las redes funcionan como una alegoría de los seres humanos atrapados en un régimen social injusto.

\footnotetext{
${ }^{46}$ En las fuentes primarias consultadas Strand se refiere abiertamente a las películas de Flaherty como antecedente importante de Redes. No hay, por otro lado, ningún indicio de que Strand conociera ; Que viva México!, la película que Sergui Eisenstein filmara parcialmente en México y que muchos comentadores sugieren influyó en la creación de Redes.
} 
Fotografía 2

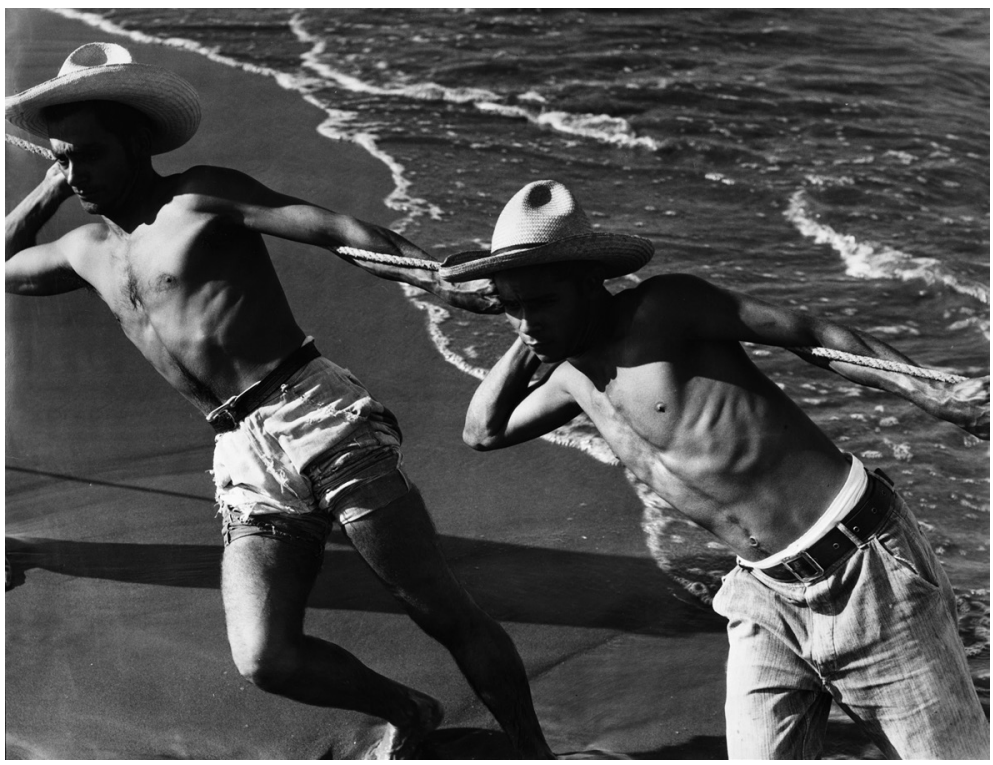

Ned Scott, foto fija, dos pescadores tirando de una red. Reproducida con autorización del Archivo Ned Scott. ${ }^{47}$

Después de la secuencia de la pesa del pescado, en la que los pescadores reciben una paga mínima, encontramos, o mejor dicho el espectador-trabajador los encuentra extendiendo y remendando las redes. Un viejo pescador apodado El Zurdo se queja: "Después de veinticinco años de trabajar por unos cuantos centavos a un hombre se le moja el cerebro y se le seca el corazón". Otro viejo pescador de nombre Felipe le aconseja, regañando, ir a la iglesia y dejar de beber, pero El Zurdo lo reta: él no está dispuesto a pagar para entrar al cielo. Beber, por lo menos "te hace olvidar a esos con sus redes y sus malditos botes; esos que tienen todo y no te dan nada". Furioso, El Zurdo ataca

${ }^{47}$ El Archivo Ned Scott puede consultarse en línea en thenedscottarchive.com. 
las redes con un cuchillo, pero Miro se adelanta para impedírselo. De esta manera el espectador es testigo de la enajenación de los pescadores respecto a su labor, algunos de los cuales se vuelven hacia el alcohol y otros a la religión que, la película sugiere siguiendo a Bassols y otros marxistas, es una fuente equívoca de bienestar. El Zurdo indica con gran claridad la causa de esta enajenación: el sistema capitalista, en el cual los botes y las redes -los medios de producción-son propiedad privada de unos, y su resultado, la diferencia de clases.

\section{Fotografía 3}

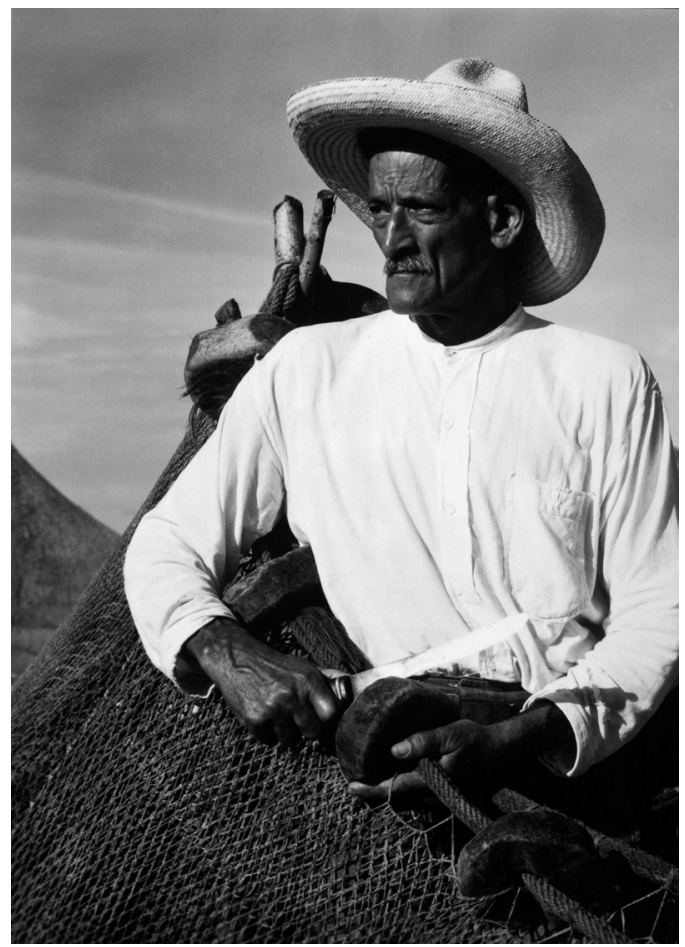

Ned Scott, foto fija, El Zurdo a punto de cortar las redes. Reproducida con autorización del Archivo Ned Scott. 
La división de la sociedad en clases antagónicas de poseedores y desposeídos se hace evidente a todo lo largo del film, así como su origen en la relativa posición que guardan los pescadores y el acaparador, don Anselmo, respecto a las fuentes de riqueza, las fuerzas de producción. Numerosas tomas de la aldea de pescadores con sus techos de paja y sus niños semidesnudos, y de pescadores sin trabajo, sus cabezas bajas por la desesperación, hacen evidente al espectador la pobreza de los mismos. Miro mismo, como muchos otros, no cuenta más que con su labor física, pero cuando intenta encontrar trabajo como estibador ya no se le necesita. En contraste con esto, el espectador puede observar a Anselmo sentado en un patio sombreado. Aprendemos a lo largo de la película que es propietario del bote más grande y las redes más nuevas, así como de máquinas de hielo, y que su negocio, de hecho, opera con éxito monetario. Con posibilidades de refrigerar y distribuir el pescado, Anselmo lo venderá a los habitantes de las ciudades a un precio mucho más alto. Gracias a su fortuna y posición Anselmo puede conspirar a su favor con el político del pueblo, el ejército lo protege cuando los pescadores entran en conflicto y tiran el pescado al suelo, y puede contratar a un "patrón” o capataz como barrera entre él y los pescadores a quienes tan despiadadamente explota.

Habiendo detenido al Zurdo en su intento de destruir las redes, Miro busca una solución alternativa a su sufrimiento y llama a todos los pescadores a una reunión para proponerles una acción colectiva. La cámara sigue a una multitud de pescadores a las dunas en que se encuentra Miro. Éste pronuncia entonces un discurso en el que, con ayuda de material cinematográfico adicional que muestra otras industrias, transporte y mercados urbanos, describe prácticamente los principios en que se basa el sistema capitalista de producción. Miro llama la atención de los pescadores al cuerpo humano, su cuerpo, como la única fuente verdadera de riqueza y explica cómo ésta se ve multiplicada por los procesos de transformación y distribución controlados por otros. El 
producto de su trabajo, sin embargo, solamente llega a las capas más altas de la sociedad y no a otros trabajadores que, como los pescadores, producen riqueza en industrias como la agricultura, el ganado o los textiles. Finalmente, Miro sugiere un modo colectivista de producción o, por lo menos -en coincidencia con las enseñanzas de Bassols-, de distribución de la riqueza, mediante intercambio directo con los productos de otros trabajadores. "La pobreza", exclama, "no es la ley de la naturaleza ni la ley de Dios”. El discurso de Miro es el clímax ideológico y educacional de la película. Los pescadores/espectadores aprenden que su situación no es inevitable: puede ser entendida como la consecuencia del capitalismo. Pertenecen a una clase explotada y como clase deben oponerse al mecanismo de explotación.

\section{Fotografía 4}

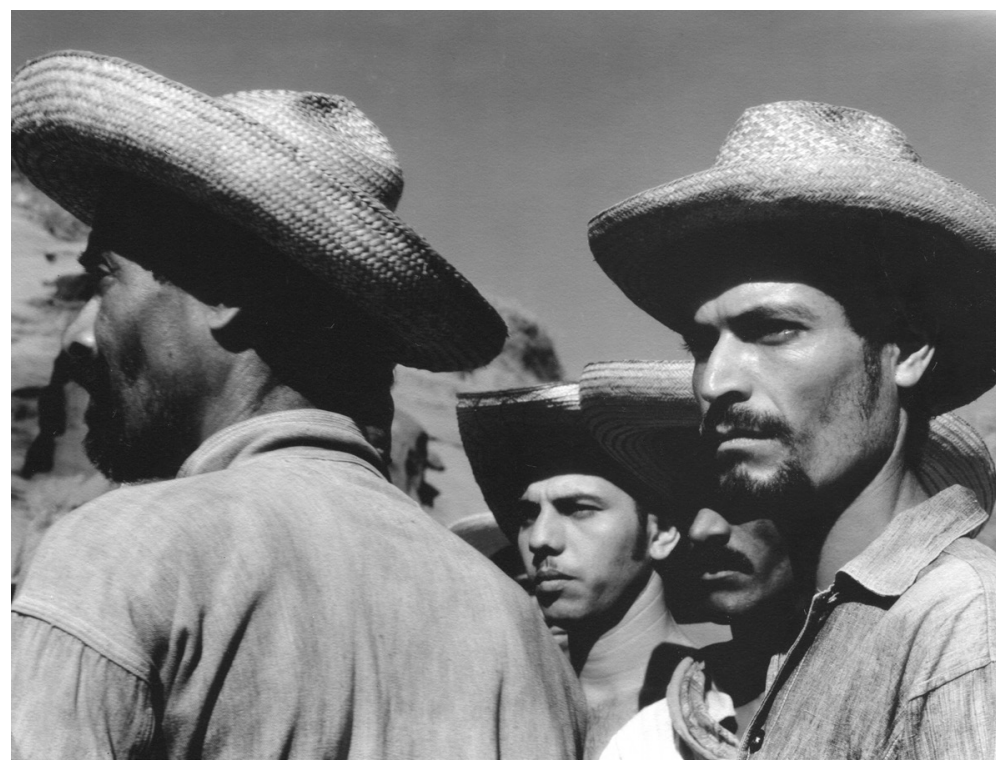

Ned Scott, foto fija, los pescadores escuchando a Miro. Reproducida con autorización del Archivo Ned Scott. 
La secuencia de la pelea entre pescadores que se unen a Miro y aquellos que no creen en la fuerza de dicha unión enseña al espectador-trabajador los peligros que esperan a los pescadores en su esfuerzo por unirse y organizarse. En una serie de tomas cortas, Miro se enfrenta al capataz Mingo y a Miguel, cabeza del grupo disidente, y los exhorta a no dejarse vencer. Pero algunos pescadores prefieren llevar a casa unos cuantos centavos que nada, y varios close-up muestran la triste resignación en sus semblantes.

Fotografía 5

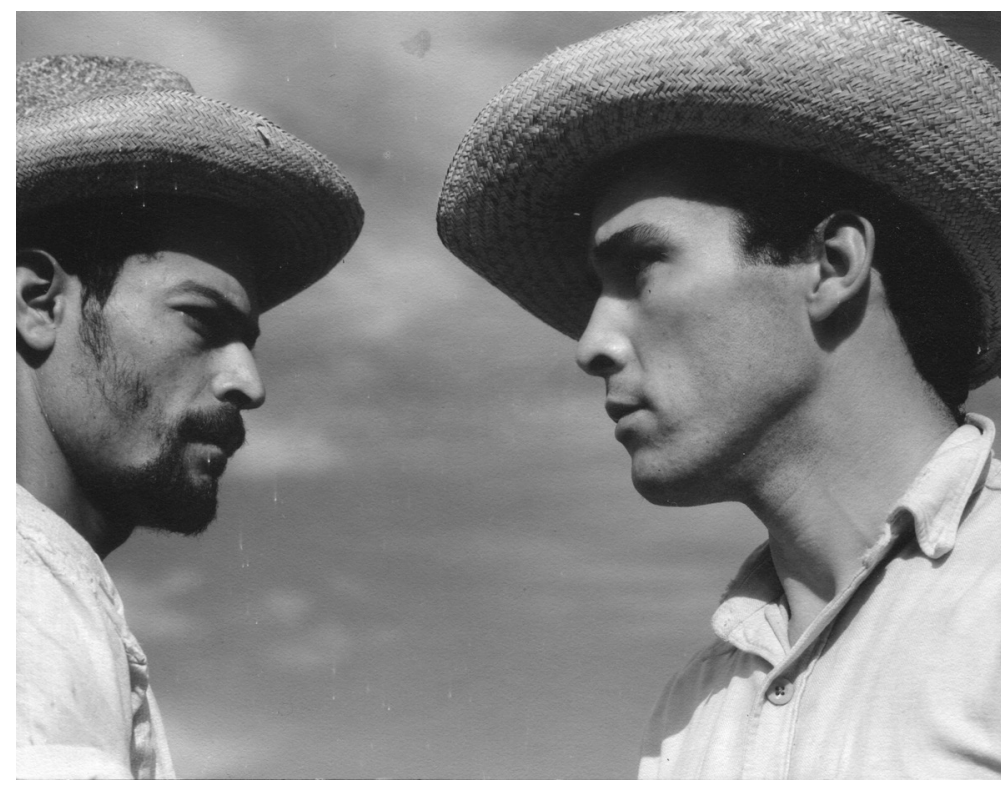

Ned Scott, foto fija, Miro y Miguel se enfrentan uno a otro. Reproducida con autorización del Archivo Ned Scott.

Cuando Miro tira el pescado al suelo y los pescadores pelean a golpes y navajas, la cámara muestra la fuerza física y la pobreza, 
reflejada en sus vestimentas rotas, que tienen en común, a pesar de la disensión temporal entre ellos. La pelea es interrumpida por el ejército, que catea a los sudorosos, ensangrentados pescadores, pero no al político que acaba de asesinar a Miro, ni a Anselmo. La película muestra a los trabajadores los peligros que les aguardan: la muerte, la intervención de las fuerzas armadas y la posibilidad de una colusión entre sus opresores políticos y sociales. Los amigos de Miro se lo llevan en un solitario bote.

\section{Fotografía 6}

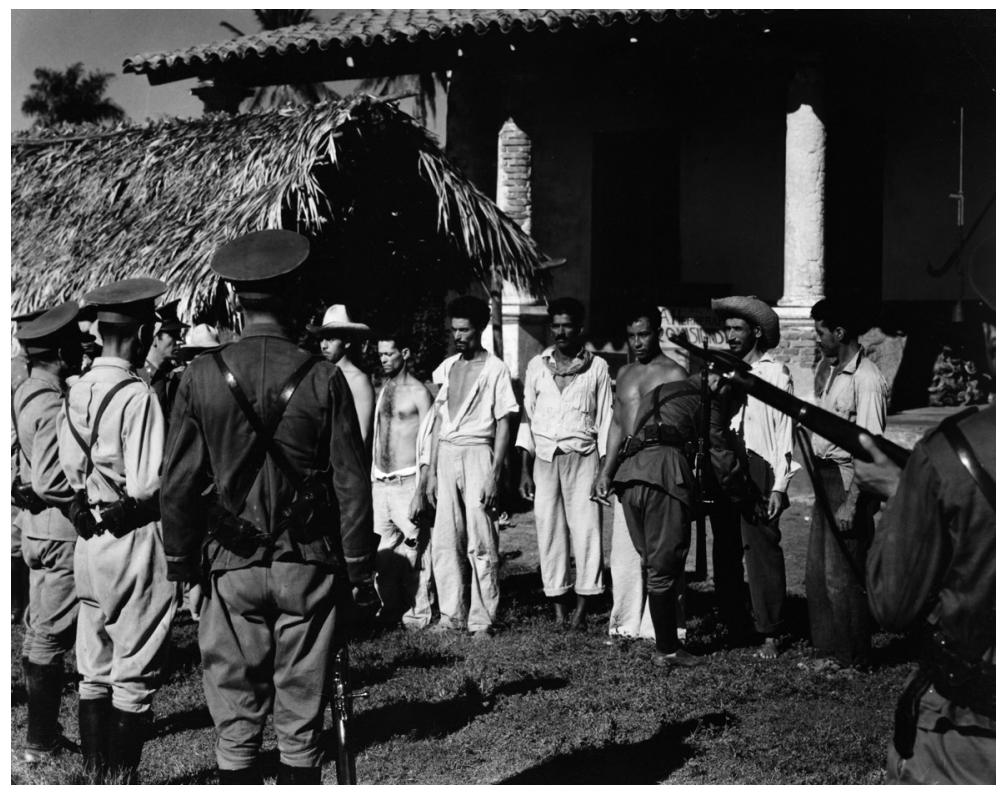

Ned Scott, foto fija, los pescadores y el ejército. Reproducida con autorización del Archivo Ned Scott.

Finalmente, en la secuencia de la reconciliación, Miguel y los pescadores disidentes toman el bote de Anselmo para llevar a Miro y sus amigos el dinero con el cual el acaparador 
había tratado de comprar su lealtad: ellos no están dispuestos a venderse ni a robar. Una serie de tomas nos muestran en un principio a los dos grupos de hombres de perfil, cara a cara, en contraste con un fondo hecho de cielo y las hojas angulares de las palmeras. Los pescadores se enteran de que Miro ha muerto. Miguel declara en forma explícita, para la educación de los espectadores-trabajadores, la necesidad de luchar juntos hasta que puedan poseer sus propios botes, redes y hielo: los medios de producción como propiedad del trabajador. En este punto, observamos a todos los pescadores marchando en la misma dirección, el cuerpo de Miro sobre sus hombros, sus caras mostrando gran determinación. Otros pescadores se les unen lentamente; la última larga toma muestra una multiplicidad de botes, atravesando las aguas rápidamente, llevando el cuerpo de Miro de regreso al pueblo.

\section{Fotografía 7}

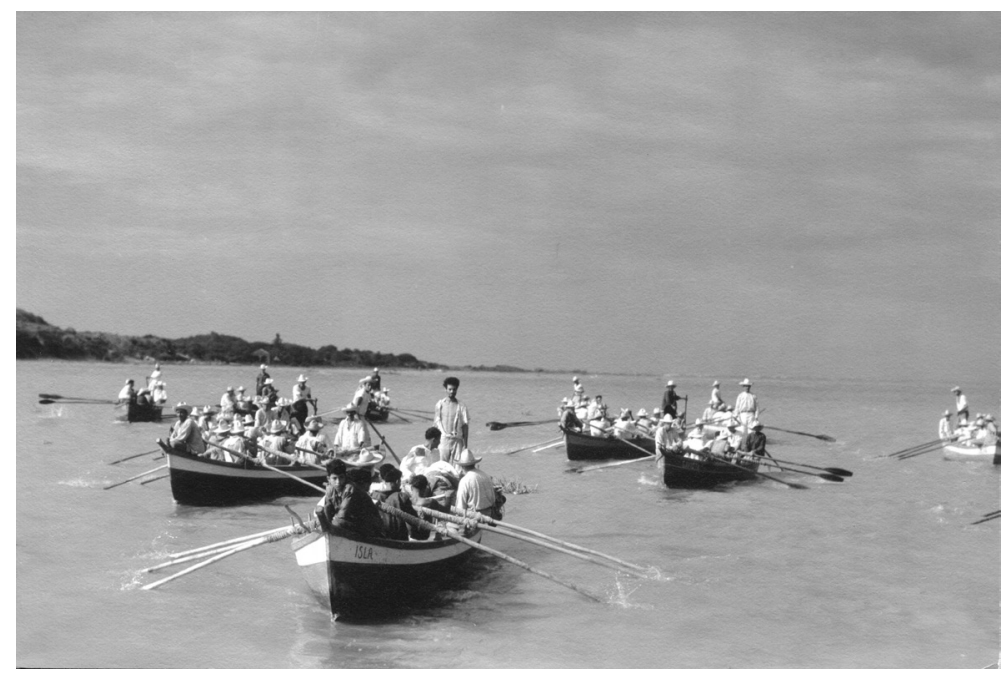

Ned Scott, foto fija, pescadores unidos atraviesan el río con el cuerpo de Miro. Reproducida con autorización del Archivo Ned Scott. 
PRODUCCIÓN E INTERVENCIÓN POLÍTICA

El contrato negociado entre el subsecretario Jesús Silva Herzog y Strand colocó la producción entera de la película bajo la dirección de Paul Strand, otorgándole el control sobre todos los materiales y gastos necesarios para completarla..$^{48}$ Huelga decir que la filmación de una película independiente, realizada por un equipo de artistas con personalidades fuertes, y sin líneas verticales de responsabilidad y autoridad, sufrió innumerables altas y bajas. Además de los problemas de índole personal, la correspondencia entre Chávez y Strand, y entre éste y sus amigos en Estados Unidos, revela contratiempos como la falta de electricidad, la falta de pesca, nortes, problemas en la frontera, la distancia con los laboratorios de Hollywood, berrinches de los actores e insolaciones. ${ }^{49}$ Chávez resolvió todos los problemas financieros y relacionados con el equipo de filmación, y se mantuvo al tanto del progreso del trabajo en Alvarado.

A pesar de los contratiempos la película avanzó. Strand, quien fue tanto el director intelectual como el cinematógrafo, trabajó con una cámara Akeley de su propiedad. Strand compartió con Chávez no sólo sus frustraciones sino también su entusiasmo por el trabajo. Por ejemplo, el 26 de febrero de 1934 escribió a Chávez para solicitar una lente de marca y dimensiones específicas. Después de reportar que el funeral del niño necesitaría un día más de trabajo una vez que pasara el norte que había, y que el equipo trabajaba muy bien y sin quejarse, Strand añadió, no sin humor,

Si pudiéramos ver algo de la película, ayudaría mucho. La mayor parte se ve muy bien en la cámara, pero hay que verla en una pared.

48 Krippner, Paul Strand in Mexico, p. 69.

49 Véase, por ejemplo, el reporte sobre los pescadores-actores en Michel Mok, "Spare the Rod and Spoil the Actress: She's Just a Simple (Not So Simple) Fishermaid, but She Went Garbo Before the Movie Camera", New York Evening Post (11 mayo 1937), y los recuerdos de Zinnemann, A Life in the Movies. 
En Hollywood ven "rushes” a la mañana siguiente, así es que ya ves qué santidad se requiere de nosotros [...] Cuando acabe la película espero haber adquirido un magnifico y brillante halo-que brille aun de día- y sea muy bonito. ${ }^{50}$

El fuerte interés del equipo entero en el proyecto, a pesar de los salarios, que eran muy bajos, se puede observar a través de la correspondencia. Strand confesó a Chávez: "El calor y la humedad en Alvarado lo abruman a uno, se llevan la vitalidad. Fred se ha ido a Orizaba a descansar por unos días; ha estado en Alvarado sin parar. Mientras tanto, los que quedamos nos estamos preparando para la próxima secuencia”. ${ }^{51}$ Otras veces, Strand reportaba que el ánimo era excelente.

Strand y Chávez discutían el filme a menudo, por carta y en las muchas ocasiones en que Strand fue al Distrito Federal donde, a decir de Chávez, pasaban horas juntos, "tostándose" al sol..$^{52}$ De estas conversaciones privadas, por supuesto y por desgracia, no queda documentación. Tal y como la vida de los pescadores, la filmación dependía de la variabilidad de la temporada de pesca. Así, el 9 de febrero Strand reportó que habían decidido empezar por la secuencia del funeral, que no requería de pescado. ${ }^{53}$ Después de una semana de lluvia habían empezado a filmar y completaron 13 escenas. Dos semanas más tarde la secuencia del funeral, que se había convertido en

50 AGN, CC, serie correspondencia personal, c. 11, vol. III, expediente 98, carta de Paul Strand a Carlos Chávez, 26 de febrero de 1934.

51 AGN, CC, serie correspondencia personal, c. 11, vol. III, exp. 98, 24 de mayo de 1934. El contraste entre la obvia entrega del equipo en el momento de la filmación y la agresividad de los comentarios posteriores por parte de Zinnemann y hasta de Strand es de lamentarse. Véase Krippner, Paul Strand in Mexico, p. 70.

${ }^{52}$ AGN, CC, serie INBA, c. 2, vol. II, exp. 27, carta de Carlos Chávez a Strand, 16 de marzo de 1934.

${ }^{53}$ AGN, CC, serie correspondencia personal, c. 11, vol. III, exp. 98, 9 de febrero de 1934. 
una parte importante de la película y no en el preludio que se planeara en un principio, estaba casi lista a pesar del mal tiempo. Strand escribió: "Nuestros hombres trabajan maravillosamente. Un gran equipo. Nada es demasiado para ellos. Sylvio [sic] (el líder) lo hace muy bien. La gente en general mucho más libre frente a la cámara de lo que pensábamos" ${ }^{54}$

Los pescadores debían ser pagados diariamente, ya fuera que actuaran o no, o se irían a desempeñar otros trabajos. Con la ayuda de Antonio Lara, un actor-pescador que se convirtió en la mano derecha de Strand, el cinematógrafo compró un bote y redes para el filme y permitió que los pescadores los usaran, compartiendo la ganancia; de esta manera Strand contó con bote, redes y pescadores. En marzo la pesca fue mejor. Las primeras 42 escenas de la secuencia de la pesca

[...] se veían muy bien en la cámara [...]. Pasamos cinco días en la playa desde temprano hasta la puesta de sol; nos trajeron la comida aquí. Fred y yo estamos muy contentos con el trabajo. Es muy demandante y lento de hacer, se lleva mucha película, pero será seguramente una de las partes estelares de la película, muy viva y bella. ${ }^{55}$

A fines de ese mes, Strand reportó los avances en esa secuencia:

Hemos [...] hecho 73 escenas desde la última vez que te vi. Esto incluye muchas escenas que han sido añadidas al guion. Tenemos grandes esperanzas en este material porque desde el punto de vista plástico ha sido muy bello. En vez de trabajar en el río, lo que habría sido más tranquilo y rápido, pero sin interés, escogimos la punta norte, donde el agua es siempre muy viva. Siento que no hayas estado aquí estas dos semanas para que te dieras una idea de

${ }^{54}$ AGN, CC, serie correspondencia personal, c. 11, vol. III, exp. 98, 26 de febrero de 1934.

55 AGN, CC, serie correspondencia personal, c. 11, vol. III, exp. 98, carta de Paul Strand a Carlos Chávez, 19 de marzo de 1934. 
cómo estamos trabajando. Hoy recibimos la lente nueva y hubo gran alegría en el equipo de filmación, ya que la necesitábamos justo en este momento. ${ }^{56}$

Además de una lente nueva, el filme se había llevado mucha más película virgen de la planeada originalmente. Chávez se hallaba en dificultades para conseguir el dinero. A sus objeciones, y quizá también a las del secretario, Strand respondió:

Estamos abordando un problema muy diferente [del de las películas mexicanas comerciales], en condiciones difíciles en cuanto al tiempo, con gente complicada no profesional, y el objetivo decidido de hacer algo muy bueno que pueda soportar la comparación con los mejores filmes [...] Me doy cuenta y aprecio tu fe en mí, y me doy cuenta de la fe que Bassols puso en ti al iniciar este proyecto [...] creo que estamos en la misma situación que en Rusia cuando empezaron sus primeros filmes. También empezaron con un estándar muy alto y lo consiguieron en Potemkin y otros filmes. Debe haberse necesitado una buena cantidad de fe por parte de los de arriba. ${ }^{57}$

A finales de marzo, Strand instó a Chávez y a Bassols a visitar el sitio:

[...] si Bassols pudiera ver Alvarado [...] las condiciones económicas a que nos enfrentamos, ver la pesca y los aspectos estéticos del lugar, que también tienen un papel en el filme [...], todo esto agudizaría su interés y su entendimiento de una película realizada bajo las condiciones y con el propósito de ésta. ${ }^{58}$

56 AGN, CC, serie correspondencia personal, c. 11, vol. III, exp. 98, carta de Paul Strand a Carlos Chávez, 27 de marzo de 1934.

57 AGN, CC, serie correspondencia personal, c. 11, vol. III, exp. 98, Paul Strand a Carlos Chávez, 19 de marzo de 1934.

58 AGN, CC, serie correspondencia personal, c. 11, vol. III, exp. 98, carta de Paul Strand a Carlos Chávez, 28 de marzo de 1934. 
Sin embargo, el 19 de mayo de 1934, con la película aún en filmación, Bassols se vio obligado a renunciar a la SEP por las confrontaciones habidas con maestros, padres de familia y la Iglesia católica a raíz de su intento de introducir educación sexual en las escuelas. Su equipo de trabajo, incluyendo a Chávez, renunciaron también y la incertidumbre se sintió en Alvarado:

[...] noticias de los acontecimientos han aparecido en los periódicos, tal como me dijiste y suponías [...] Es difícil no pensar en ti como nuestro Jefe. Naturalmente me siento muy extraño en este periodo incierto $[\ldots]$ no quiero quejarme $[\ldots]$ tengo bastante fe en [la secuencia del] mitin, arriba en las dunas, bajo este sol ardiente. ${ }^{59}$

Una nueva administración se puso en marcha cuya violencia hacia la administración de Bassols y Chávez llama la atención, aun en México. ${ }^{60}$ Antonio Castro Leal, nuevo jefe del DBA, canceló el plan de filmación de películas; sin despedir a Strand de la Oficina de Cine, creó otra oficina que puso a cargo de Velázquez, pidió un reporte de la filmación que Velázquez mismo escribió después de una visita a Alvarado en junio, y dio un ultimátum a Strand para terminar la película en diciembre bajo la amenaza de suspender todos los fondos. ${ }^{61}$

No hay documentación administrativa que especifique que Chávez escribiría la música para Pescados, pero la película se filmó explícitamente para el cine sonoro, y era asumido por todos que Chávez estaría a cargo de la música. Todavía el primero de agosto Chávez y Strand planeaban la musicalización de la

59 AGN, CC, serie correspondencia personal, c. 11, vol. III, exp. 98, carta de Paul Strand a Carlos Chávez, 24 de mayo de 1934.

60 No es descabellado pensar que Castro Leal estuviera colocándose en posición de ser incorporado al gobierno de Lázaro Cárdenas, quien tomaría posesión en unos meses, y que hubiera visto un rival en Chávez y sus posiciones de izquierda.

61 KrIPPNER, “Traces, Images and Fictions”, p. 379. 
película con el apoyo financiero de Bassols desde la Secretaría de Hacienda: "[Bassols] me dijo que conseguirá el dinero para la parte musical. Debemos tener lista la parte muda de la película entera lo antes posible. Quiero tener una descripción clara de todas las escenas y secuencias en su última versión". ${ }^{62}$

Ese mes, sin embargo, sin consulta previa y sin aviso, Velázquez arrancó de manos de Chávez la tarea de componer la música y se la ofreció a Revueltas. Castro Leal le explicó a Chávez a posteriori que había asumido, sin consultarlo, que dado que éste estaba componiendo la música para la inauguración del Palacio de Bellas Artes, no tendría tiempo de escribir la música para la película; además, habiendo sido jefe de Velázquez, no le sería posible ahora estar bajo sus órdenes. ${ }^{63}$ Furioso y herido, Chávez recriminó a Strand lo que asumió era una falta de apoyo. Strand no sabía que Chávez no había estado de acuerdo con el cambio, y el 25 de agosto escribió: "Estoy sorprendido y afligido de recibir tu carta [...] nunca se me ocurrió que nadie más que tú escribiría la música [...] tú sabes que tu música me llega profundamente y que quería que fuera parte, una parte muy importante, de la película. Sé cuánto entusiasmo tenías por hacerla, y qué desilusión tan grande esto es para ti, como para mí también" ${ }^{64}$

Strand terminó la filmación en diciembre y salió del país, perdiendo el control sobre el resultado final de su proyecto. Una vez en Nueva York, él mismo pagó las reparaciones que necesitó su cámara. Los salarios de Rodakiewicz y Zinnemann cesaron abruptamente y se vieron obligados a pedir prestado el dinero para su repatriación. Chávez regresó a la dirección del Conservatorio hasta que, en diciembre del mismo año, de

62 AGN, CC, serie correspondencia personal, c. 11, vol. III, exp. 98, carta de Carlos Chávez a Paul Strand, 1ㅇ de agosto de 1934.

63 AGN, CC, serie correspondencia personal, c. 11, vol. III, exp. 98, carta de Antonio Castro Leal a Chávez, 20 agosto de 1934.

64 AGN, CC, serie correspondencia personal, c. 11, vol. III, exp. 98, carta de Paul Strand a Carlos Chávez, 25 de agosto de 1934. 
nuevo sin previo aviso y sin documentación alguna que explicara el cambio, Estanislao Mejía se presentó en su oficina para tomar posesión de ella. A partir de 1935 Chávez se dedicó a la composición y a la dirección artística y ejecutiva de la osm, y no volvió a ocupar un puesto en el gobierno mexicano sino hasta 1947 , viviendo, fundamentalmente, de su carrera nacional e internacional como director de orquesta. ${ }^{65}$ Strand vio Redes en su forma final cuando la película se estrenó en Nueva York en 1937; Chávez se negó a verla hasta 1973.

\section{LA MÚSICA COMO MENSAJE POLÍTICO}

Bella y expresiva como lo es, la música de Revueltas es incidental al proyecto de la película, en cuya gestación y realización Revueltas no participó. Por otra parte, Revueltas conoció el contenido de la película y escribió la música con el argumento en mente. ${ }^{66}$ Revueltas viajó a Alvarado en septiembre de 1934, donde, a pesar de haberse comportado, en sus mismas palabras, un poco tontamente, se inspiró no por la música que hubiera podido escuchar, es decir, por el son jarocho típico de Alvarado, sino por el ethos de la película y la presencia de los pescadores, lo que seguramente estaba en resonancia con sus propias ideas políticas. ${ }^{67} \mathrm{Su}$ banda sonora para Redes utiliza un vocabulario que Revueltas había desarrollado en los últimos cuatro años en su música de concierto y con el cual solía llevar a su público a través de estados emocionales violentos y contrastantes. Es un vocabulario de ritmos, colores instrumentales y fragmentos melódicos que Revueltas había construido para representar sónicamente a grupos desposeídos, para codificar musicalmente a México

${ }^{65}$ La osm, orquesta privada de capital mixto, no participó, como es natural, en la grabación de la banda sonora de Redes.

${ }^{66}$ Contreras Soto, Silvestre Revueltas en escena, pp. 96-100 y 106-108.

${ }^{67}$ CCP, PSC, Archive Group 17: 18, serie correspondencia personal, exp. 28, carta de Silvestre Revueltas a Paul Strand, 16 de septiembre de 1934. 
y representar de manera transmedializada un medio ambiente sonoro que podía incluir ruidos, gritos, insultos y fragmentos cortos de músicas callejeras. ${ }^{68} \mathrm{Al}$ igual que el construccionismo visual de Strand, la música de Revueltas es modernista sin ambages, pero sus diferentes significadores la anclan en una realidad expresiva y sonora fácilmente reconocible por un mexicano, especialmente en los años treinta.

Redes se encuentra a caballo entre las épocas silentes y sonoras del cine; como tal, incorpora un diálogo apenas presente en tomas lentas de gran intensidad visual, y permite así que la música facilite el desarrollo del argumento. ${ }^{69} \mathrm{La}$ música casi nunca es simultánea al diálogo y en cambio se mueve con fuerza al primer plano narrativo en las secuencias más importantes. Como ha mencionado Jacqueline Ávila, Revueltas utiliza leitmotivs, un recurso del cine mudo derivado de la ópera, en particular la wagneriana, para dar color emocional a momentos cruciales de la película y ayudar a los espectadores a seguir tanto la narrativa como el mensaje ideológico. Finalmente, Revueltas incorpora rápidos segmentos de transición y ostinati para hacer avanzar escenas con poca acción visual. ${ }^{70}$

La banda sonora es muy didáctica, como correspondería a una película para la educación de las clases trabajadoras; Revueltas refuerza directamente el mensaje político de la narrativa empleando ya sea un puñado de leitmotivs abstractos que ligan musicalmente unos pasajes de la película con otros, estableciendo una conexión emotiva y cognitiva, o bien significadores

${ }^{68}$ Véase el trabajo de Roberto Kolb sobre la transmedialidad en Revueltas: Kolb, Contracanto, passim.

${ }^{69}$ Revueltas había trabajado como músico y director de orquesta en salas de cine mudo en Estados Unidos. Véase Parker, "Revueltas in San Antonio".

70 Jacqueline Ávila, "Revueltas and the Cinema", ponencia leída en la reunión anual de la Society for American Music, San Antonio, 2008. Agradezco a Jacqueline Ávila el haber compartido el texto conmigo. 
musicales ya establecidos por él y otros compositores mexicanos que apuntan a referentes contextuales y sociales. ${ }^{71}$

Por ejemplo, mientras la pantalla muestra los créditos con el trasfondo de una serie de olas rompiendo sobre la arena escuchamos un leitmotiv en forma precisamente de ola, con un ascenso rápido y un descenso cromático que crea ya una atmósfera dramática que más adelante aprenderemos a asociar con escenas en que los pescadores se ven abatidos por circunstancias ajenas a su control (ejemplo 1). El motivo de la ola aún suena en nuestros oídos cuando un segundo motivo disonante, que los espectadores-trabajadores asociaremos a su vez con peces o bien con hombres atrapados en redes o sistemas económicos injustos, aparece en los metales bajos (ejemplo 2). ${ }^{72}$

\section{Ejemplo 1}

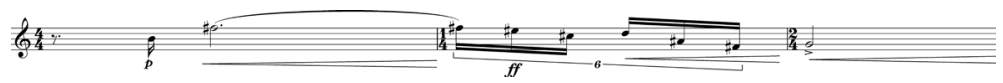

Revueltas, Redes, Parte I, compases 1-2, trompeta en do. Leitmotiv "ola/destino".

\section{Ejemplo 2}

\section{tc}

Revueltas, Redes, Parte I, compases 6-7, corno en fa. Leimotiv “redes”.

71 Otros análisis de la música, que no excluyen el presentado aquí, se encuentran en Contreras Soto, Silvestre Revueltas en escena, pp. 147-172; y KolbNeuhaus, “Silvestre Revueltas's Redes”, pp. 130-142.

72 Los ejemplos musicales están tomados de la partitura publicada por Southern Music Publishing Co. para facilitar su publicación. Dicha partitura no presenta la música de Revueltas tal y como aparece en la banda sonora del film. Sin embargo, los ejemplos representan fielmente los temas a los que aludo. Mis comentarios sobre el papel de la música en el film se basan en mi propia percepción -como músico profesional-de la misma. 
Mientras observamos a Miro y El Zurdo caminar hacia el pueblo en busca de trabajo, pasando por casuchas con niños a las puertas, un ostinato trémolo en las cuerdas bajas ilustra su caminar. No es un caminar animado, los personajes no abrigan grandes esperanzas y el camino puede resultar largo. La melodía amarga y dulce de la flauta tiene la forma de arco y el intervalo cadencial de tercera que eran arquetípicas en la música mexicana como indicadores de la canción rural mexicana (ejemplo 3). Ésta, a su vez, era entendida como la música de los desposeídos ya desde el trabajo de Manuel M. Ponce en la década de 1910, es decir, era una forma de conocimiento de lo social mexicano que había circulado y se había sedimentado como tal desde los años de popularidad de la canción en los años veinte. ${ }^{73}$

\section{Ejemplo 3}

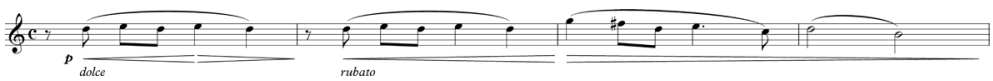

Revueltas, Redes, Parte I, compases 24-27, flauta. Melodía en estilo de canción mexicana; significador musical de "el pueblo".

Revueltas emplea un segundo significador de "el pueblo", igualmente bien establecido por la música nacionalista de concierto de los años veinte y treinta: el arquetipo de un son, común a varias tradiciones musicales del occidente de México, caracterizado por su métrica compuesta, y la presencia de síncopas y hemiolas (ejemplo 4). En la secuencia de la pesca, este son tiene

73 Véase SaAvedra, "Manuel M. Ponce y los músicos", SaAvedra, "Manuel M. Ponce's Chapultepec", y Leonora Saavedra, "Producción, circulación y negociación del conocimiento social de lo mexicano a través de la música en la década de 1920", conferencia dictada como parte de la Cátedra Jesús C. Romero en el Centro Nacional de Investigación, Documentación e Información Musical “Carlos Chávez”, Ciudad de México, octubre de 2016. 
la doble función de fanfarria, anunciando la pesca, y celebración por su llegada. Mientras que el son, como género dancístico, resultaría un tanto incongruente en una escena sobre el agua, su arquetipo funciona por la asociación establecida previamente en la música de concierto de este género con el pueblo, la vida rural y la celebración jubilosa, es decir, Revueltas utiliza, de nuevo, una elaboración sónica, ampliamente conocida, de un conocimiento de lo social mexicano.

\section{Ejemplo 4}

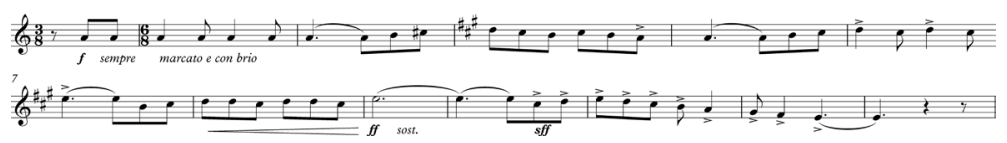

Revueltas, Redes, Parte I, compases 143-155, trompeta en Do. Melodía en estilo de son mexicano; significador musical de "la alegría del pueblo".

Una dolorosa tercera menor en el clarinete y la flauta con un pulso subyacente de las cuerdas es la música fúnebre para el entierro del hijo de Miro (ejemplo 5). Una disonancia llama nuestra atención emotiva hacia la madre doliente y cede eventualmente a unos suaves cornos que imitan el repicar de campanas (demostrando de paso las dotes de orquestador de Revueltas). Esta música fúnebre se convierte, reorquestada, en el leitmotiv de la muerte, que escuchamos de nuevo en el momento en que Miro cae a consecuencia del disparo y posteriormente, cuando los pescadores disidentes son informados de su muerte. Este leitmotiv acompaña también la larga toma de los botes llevando a Miro de regreso al pueblo, con lo que la narrativa se cierra sónicamente sobre sí misma, volviendo a la tragedia inicial de la muerte del niño. El leitmotiv relaciona cognitiva y emocionalmente para los espectadores-trabajadores a la muerte y la tragedia, aparentemente sólo personal, con las consecuencias de la injusticia social. 


\section{Ejemplo 5}

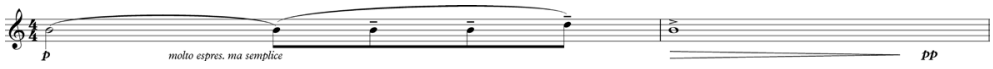

Revueltas, Redes, Parte I, compases 43-44, clarinete en si bemol. Leitmotiv "funeral/muerte".

Revueltas utiliza su estilo modernista característico y su técnica compositiva de collage para ilustrar el caos y la violencia de la pelea: disonancias, yuxtaposiciones abruptas y motivos cortos que mimetizan ruidos, gritos, insultos y golpes. Los acentos a contratiempo y las repeticiones de acordes aparentemente al azar son reminiscentes de la Consagración de la Primavera de Igor Stravinsky. Al final de esta secuencia, el motivo inicial de la ola/destino se escucha en los metales, y enseguida en la flauta.

Al terminar esta secuencia, un motivo que podríamos asociar con la fe en la unión aparece cuando vemos a los camaradas de Miro en la escena final de la reconciliación de todos los pescadores. Al llevar éstos el cuerpo límpido de Miro hacia los botes, la banda sonora se apodera una vez más de la narrativa. Un ostinato lúgubre subraya el movimiento de los remos hundiéndose en el agua; inicialmente en las cuerdas graves, el ostinato es llevado eventualmente a toda la orquesta. Escuchamos en los metales la parte descendente del motivo de la ola/destino, en aumentación rítmica, que es confrontado, por así decirlo, y finalmente abatido por el fuerte impulso ascendente del motivo de la esperanza/ unión (ejemplo 6).

\section{Ejemplo 6}

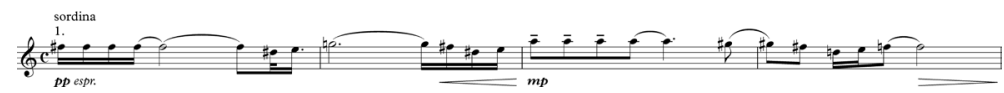

Revueltas, Redes, Parte II, compases 77-80, trompeta en do. Leitmotiv "fe en la unión". 
De esta manera la música de Revueltas incorpora prácticas de cine silente, como el uso de leitmotivs, para dar coherencia interna al contenido ideológico-emocional de la narrativa, así como prácticas de la música de concierto, con su colección de significadores musicales que apuntan, si bien de manera simbólica, e incluso estereotipada, a una realidad exterior bien conocida de los mexicanos, y por lo tanto, de las clases trabajadoras. La música refuerza emocionalmente el mensaje político que a nivel cognitivo es remitido al espectador-trabajador por el diálogo y la acción.

\section{DESPUÉS DE REDES}

Cuando Strand volvió a Nueva York a principios de 1935, encontró con alegría que el Group Theatre de Clurman estaba en pleno apogeo y se incorporó a su mesa directiva. Después de un viaje a Moscú se unió con Leo Hurwitz y Ralph Steiner como escritor y cinematógrafo de The Plow that Broke the Plains, un documental sobre la desolación del llamado "tazón de polvo" de los estados centrales de Estados Unidos, desastre ecológico causado por la "ambición desmedida del hombre por arar tierras que no eran aptas para ser labradas". ${ }^{74}$ Juntos fundaron Frontier Films, una organización sin propósito de lucro para la realización de documentales sobre problemas sociales complejos, con un fuerte mensaje político y social, que "nuestros compatriotas debían conocer". ${ }^{75}$ En 1937 comenzó The Native Land, sobre la violación de los derechos civiles en Estados Unidos, terminada hasta 1942 por falta de fondos. El 1o de noviembre de 1938, Strand escribió a Chávez sobre la dificultad de conseguir financiamiento. Y añadió:

${ }^{74}$ Citado en Tomkins, "Profiles”, p. 159.

75 Citado en Tomkins, "Profiles", p. 159. 
Debemos seguir adelante con la que tal vez sea la película más importante que se haya hecho aquí [...] una dramatización de lo que significa nuestra heredada libertad en términos del vivir actual [...] Creo que un artista puede hacer 'propaganda' efectiva haciendo arte. Y este problema estético es, estoy convencido, el problema más estimulante y más urgente al que se enfrenta hoy en día el artista. Redes comenzó este pensar y esta tarea para mí. Lo que significa que fuiste tú el que me hizo pensar y actuar en esta dirección. ${ }^{76}$

Chávez, por su parte, habiendo sido expulsado del servicio público por la maniobra política de Antonio Castro Leal, no fue llamado por el gobierno de Lázaro Cárdenas, y el plan quinquenal no dio a luz un segundo filme. En 1947, Chávez fundó y dirigió el Instituto Nacional de Bellas Artes durante la administración de Miguel Alemán; sin embargo, aunque seguía interesado en un arte para el pueblo, políticamente se había desplazado hacia el centro, e incluso el centro-derecha. En agosto de 1954, en plena Guerra Fría, le fue negada una visa a Estados Unidos por sus previas actividades políticas; con la intervención de la embajada de Estados Unidos en México se le condonó su inelegibilidad, “especialmente en vista de que el Señor Chávez niega que sea o haya sido nunca un comunista”. ${ }^{77}$

En cuanto a Redes, cuando en 1934 el pescador actor Antonio Lara conoció el guión de la película, expresó: "tiene alma". ${ }^{78}$ Sin embargo, aunque el resto de los pescadores actores vieron algunas de las tomas, proyectadas sobre una pared en la casa que habitaban Strand y su equipo, los habitantes de Alvarado, hasta donde sabemos, nunca vieron la película entera. De acuerdo a

${ }^{76}$ Carta de Strand a Chávez, 1o de noviembre de 1938. No he podido localizar el original de esta carta y reproduzco aquí la traducción que se encuentra en Carmona (ed.), Epistolario selecto, p. 279.

77 "Visa for Chavez approved by U.S.", New York Times (17 ago. 1954).

78 AGN, CC, serie correspondencia personal, c. 11, vol. III, exp. 98, carta de Paul Strand a Carlos Chávez, 27 de enero de 1934. 
Emilio Gómez Muriel, ciertas tomas provocaron protestas por su falta de fidelidad a la manera en que los pescadores manejaban la pesca o se movían en su vida cotidiana. ${ }^{79}$ De hecho, mucho del contenido político, incluso el discurso de Miro, no fueron revelados completamente a los pescadores debido a los conflictos políticos y laborales existentes al momento en el estado de Veracruz. ${ }^{80}$

Redes se estrenó en cines en México en 1935 y viajó a Estados Unidos y a Europa en años posteriores. Redes y sus películas hermanas estaban destinadas a los cientos de escuelas federales de la SEP, y es sensato suponer que también se proyectarían en las escuelas nocturnas para trabajadores. Sin embargo, hasta donde sabemos, Redes nunca fue proyectada específicamente para los trabajadores a quienes estaba dirigida originalmente. No obstante, el mensaje colectivista de la película, la documentación de la pesca como actividad productora de riqueza por la labor física del hombre, la presentación didáctica de los nuevos derechos de asociación de los trabajadores, e incluso su ritmo sumamente lento y las largas tomas de las caras estoicas de los pescadores, que habrían ayudado a espectadores no familiarizados con el lenguaje cinematográfico a encontrarle sentido: todo en Redes se entiende cabalmente cuando entendemos también que su público verdadero son las clases trabajadoras de los años treinta. Las ideas sociales/socialistas de corte marxista y los objetivos estéticos encapsulados en Redes se convierten en un mensaje no sólo real sino también preciso-y no un panfleto amorfo del realismo socialista - solamente en el contexto del pensamiento social que guiaba a la SEP de Bassols y al DBA de Chávez. La militancia activista, por medio de la educación

${ }_{79}$ Véase cita de una entrevista de Gómez Muriel con Raquel Tibol en 1954 en Contreras Soto, Silvestre Revueltas en escena, p. 137.

${ }^{80}$ Krippner, “Traces, Images and Fictions”, p. 378. 
federal de estos dos personajes, crea para nosotros un contexto complejo y bien situado históricamente para entender Redes.

\section{SIGLAS Y REFERENCIAS}

AGN, CC Archivo General de la Nación, fondo Carlos Chávez, Ciudad de México, México.

CCP, PSC Center for Creative Photography, Paul Strand Collection, Universidad de Arizona, Tucson, Estados Unidos.

Aguilar Monteverde, Alonso (comp. y estudio introductorio), Narciso Bassols, pensamiento y acción (antología), México, Fondo de Cultura Económica, 1995.

Bassols, Narciso, “Conferencia sobre las Misiones Culturales. Memoria [de la SEP] de 1932, t. I, p. 128, 20 de febrero de 1932”, en La Obra Educativa de Narciso Bassols, México, Patria, 1934, pp. 163-176.

Bassols, Narciso, "El problema educativo de México”, en Silva Herzog (ed.), 1964, pp. 170-80.

Bassols, Narciso, “Sobre teatro”, en Silva Herzog (ed.), 1964, pp. 297-300.

Bitrán, Yael y Ricardo Miranda (eds.), Diálogo de resplandores: Carlos Chávez y Silvestre Revueltas, México, Consejo Nacional para la Cultura y las Artes, 2002.

BritTon, John A., Educación y radicalismo en México, I. Los años de Bassols (1931-1934), México, Secretaría de Educación Pública, 1976.

Busselle, Rebecca y Trudy Wilner Stack, Paul Strand, Southwest, Nueva York, Aperture Foundation, 2004.

Carmona, Gloria (ed.), Carlos Chávez. Escritos periodísticos (1916-1939), en Obras completas, México, El Colegio Nacional, 1997, vol. I.

Carmona, Gloria (ed.), Epistolario selecto de Carlos Chávez, México, Fondo de Cultura Económica, 1989.

Contreras Soto, Eduardo, Silvestre Revueltas en escena y en pantalla. La música de Silvestre Revueltas para el cine y la escena, México, Instituto Nacional de Bellas Artes, 2012. 
Contreras Soto, Eduardo, “Tres propuestas revueltianas en 2004”, en Revista electrónica Redes: Música y Musicología desde Baja California, 2: 1 (ene.-jun. 2007), pp. 99-108 (accesible en: www.redesmusica.org/no2).

García Riera, Emilio, Historia documental del cine mexicano, México, Era, 1969.

Ноок, Sydney, Towards the Understanding of Karl Marx, Nueva York y Londres, John Day Company, 1933.

Kolв Neuhaus, Roberto, Contracanto: una perspectiva semiótica de la obra temprana de Silvestre Revueltas, México, Universidad Nacional Autónoma de México, 2012.

Kolb-Neuhaus, Roberto, “Silvestre Revueltas's Redes: Composing for Film or Filming for Music?", en The Journal of Film Music, 2: 2-4 (2009), pp. 127144.

Kolb, Roberto, "Los tres caminos de la subversión", en notas para el CD Silvestre Revueltas, pp. 9-26.

Krippner, James, “Traces, Images and Fictions: Paul Strand in Mexico, 19321934”, en The Americas, 63: 3 (2007), pp. 359-383.

Krippner, "Carlos Chávez and Paul Strand”, en Saavedra (ed.), 2015, pp. 220-236.

Krippner, James, Paul Strand in Mexico, México, Aperture Foundation, Fundación Televisa, 2010.

Luna Arroyo, Antonio (recolec. y estudio preliminar), La obra educativa de Narciso Bassols: documentos para la Historia de la Educ. [sic] en México. Declaraciones, discursos, decretos, tesis y acuerdos, México, Patria, 1934.

Naggar, Carole y Fred Ritchin (eds.), México Through Foreign Eyes Visto por ojos extranjeros, 1850-1990, Nueva York, W.W. Norton, 1993.

PARKer, Robert, "Revueltas in San Antonio and Mobile", en Latin American Music Review/Revista de Música Latinoamericana, 23: 1 (2002), pp. 114-130.

Paz Sánchez, Fernando (prol., sel. y notas), Vida y pensamiento de Narciso Bassols, México, Nuestro Tiempo, 1986. 
Raby, David L., Educación y revolución social en México (1921-1940), México, Secretaría de Educación Pública, 1974.

Revueltas, Eugenia, "La Liga de Escritores y Artistas Revolucionarios y Silvestre Revueltas”, en Bitrán y Miranda (eds.), 2002, pp. 174-181.

Reyes, Aurelio de los, Medio siglo de cine mexicano, 1896-1947, México, Trillas, 1988.

Rohrbach, John, “Art for Society's Sake: Paul Strand's Photographic Visions", tesis de doctorado en historia, 2 vols., Delaware, University of Delaware, 1993.

Rosenblum, Naomi, “Strand/Mexico”, en Naggar y Ritchin (eds.), 1993, pp. 26-30.

SaAvedra, Leonora, "Manuel M. Ponce y los músicos populares", en Heterofonía, 143 (2010), pp. 51-84.

SaAvedra, Leonora, "Manuel M. Ponce's Chapultepec and the Conflicted Representations of a Contested Space", en The Musical Quarterly, 92 (2009), pp. 279-328.

SaAvedra, Leonora, "The American Composer in the 1930s: The Social Thought of Seeger and Chávez”, en Yung y ReEs (eds.), 1999, pp. 29-63.

SaAvedra, Leonora (ed.), Carlos Chávez and his World, Princeton, Princeton University Press, 2015, traducción española, Carlos Chávez y su mundo, México, El Colegio Nacional, 2018.

Silva Herzog, Jesús (ed.), Narciso Bassols. Obras, México, Fondo de Cultura Económica, 1964.

Silvestre Revueltas, Orquesta Sinfónica de la Universidad de Guanajuato, José Luis Castillo, director, CD Quindecim QP123.

Stange, Maren (ed.), Paul Strand: Essays on His Life and Work, Nueva York, Aperture, 1990.

STRACHEY, John, The Coming Struggle for Power, Nueva York, Covici, Friede, 1933. 
STRAND, Paul, "El significado de la pintura infantil”, en Catálogo de la primera exposición de pintura de los Centros Culturales, pp.s.n.

Strand, Paul, Photographs of Mexico, Nueva York, Virginia Stevens, 1940.

Strand, Paul y Calvin Tomkins, Paul Strand: Sixty Years of Photographs: excerpts from correspondence, interviews, and other documents, Nueva York, Aperture, 1976.

Szegedy-Maszak, Andrew, Toward a Deeper Understanding: Paul Strand at Work, Nueva York, Aperture Foundation, 2007.

Teibler-Vondrak, Antonia, Silvestre Revueltas Musik für Bühne und Film, Viena, Böhlau Verlag, 2011.

Tomkins, Calvin, "Profiles: Look to the Things Around You", The New Yorker (16 sep. 1974), pp. 44-94.

Trachtenberg, Alan, “Introduction”, en Stange (ed.), 1990, pp. 1-18.

Vaughn, Mary Kay, La política cultural de la revolución, México, Fondo de Cultura Económica, 2000.

VÁzquez de Knauth, Josefina, Nacionalismo y educación en México, México, El Colegio de México, 1970.

Yung, Bell y Helen Rees (eds.), Understanding Charles Seeger: Pioneer in American Musicology, Urbana, University of Illinois Press, 1999.

Zinnemann, Fred, A Life in the Movies: An Autobiography, Nueva York, Macmillan, 1992. 
